\title{
Investigation on Crack Coalescence Behaviors for Granite Containing Two Flaws Induced by Cyclic Freeze-Thaw and Uniaxial Deformation in Beizhan Iron Mining, Xinjing, China
}

\author{
Y. Wang $(\mathbb{D}$ and C. H. Li \\ Beijing Key Laboratory of Urban Underground Space Engineering, Department of Civil Engineering, School of Civil \& \\ Resource Engineering, University of Science \& Technology Beijing, Beijing 100083, China \\ Correspondence should be addressed to Y. Wang; good541571889@126.com
}

Received 19 October 2019; Accepted 16 January 2020; Published 6 February 2020

Academic Editor: Andrea Brogi

Copyright (c) 2020 Y. Wang and C. H. Li. This is an open access article distributed under the Creative Commons Attribution License, which permits unrestricted use, distribution, and reproduction in any medium, provided the original work is properly cited.

\begin{abstract}
This work is aimed at investigating the effect of freeze-thaw (F-T) cycle on the crack coalescence behavior for granite samples containing two unparallel flaws under uniaxial compression. The flaw geometry in the samples was a combination of an upper inclined flaw with a horizontal flaw underneath. After the uniaxial compression experiments, macroscopic crack pattern description and the mesoscopic posttest CT imaging were used to reveal the effects of F-T cycle on the crack coalescence morphology at the rock bridge area. Results show that the stress-strain curves present a fluctuating growth trend and stress drop phenomenon becomes weaker with increasing F-T cycles. In addition, three different kinds of cracks (tensile-wing cracks, oblique shear cracks, and antiwing cracks) were observed, and the crack coalescence pattern was influenced by the F-T cycles and approach angle. A mix of tensile and shear failure occurs for the sample subjected to weak F-T treatment, and simple tensile failure occurs for the sample subjected to high F-T treatment. Moreover, CT imaging reveals a crack network pattern at the rock bridge area, and it is found that the fracture degree deceases with increasing F-T cycles and increases with the increasing approach angle. It suggests that the rock bridge area can be easily fractured for the sample subjected to high F-T cycles. Results of this study can provide theoretical foundation for the instability predication of fractured rock structures in cold regions.
\end{abstract}

\section{Introduction}

The demand for the metal mineral resources grows continuously in China nowadays, while the amount of mineral resources in the low-altitude areas is decreasing gradually $[1,2]$. The exploitation and utilization of the metal mineral have gradually moved to the high-altitude cold regions (e.g., Tibet, Xinjiang, and Yunnan), making frost-related rock mechanical problem a significant issue. In cold regions, under repeated freeze-thaw (F-T) conditions, the rock geomechanical properties would deteriorate via frost heaving after F-T cycles. The F-T process includes repeated phase transformation of water and ice, and F-T testing is usually to be used to mimic the natural weathering of rock under a low temperature in the laboratory. When water turns to ice, a $9 \%$ volumetric expansion can produce an increase in the frost heaving pressure within the pores and microcracks [3-9], this accelerates the damage of rock.

Numerous studies have been devoted to investigate the effects of F-T actions on the geomechanical properties of rock, including F-T cycles, the F-T temperature, and type of saturated solutions [8-14]. However, most of the studies are focused on intact rock. As is known, natural rock contains plenty of discontinuities, such as fissures, flaws, joints, weak surface, cracks, and faults [15-22]. The preexisting cracks or discontinuities have a significant effect on the deformation, strength, and crack coalescence. Especially, large frost heaving stress generates in the discontinuities if the flaw is fully of water, as a $9 \%$ volumetric expansion occurs when water changes to ice, the existence of those flaws accelerates the deterioration of rock F-T fatigue damage. The mechanical behaviors of rock containing preexisting flaws have been 


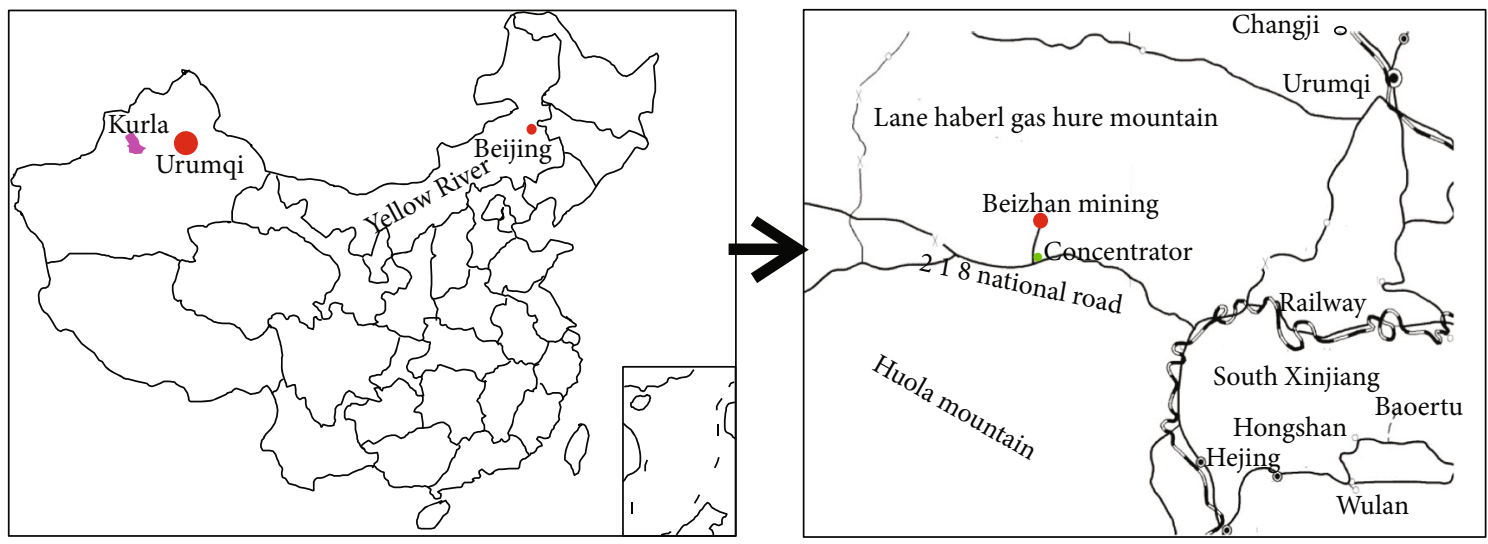

Figure 1: Location of the Hejing Beizhan Iron Mining in the Xinjing province, China.

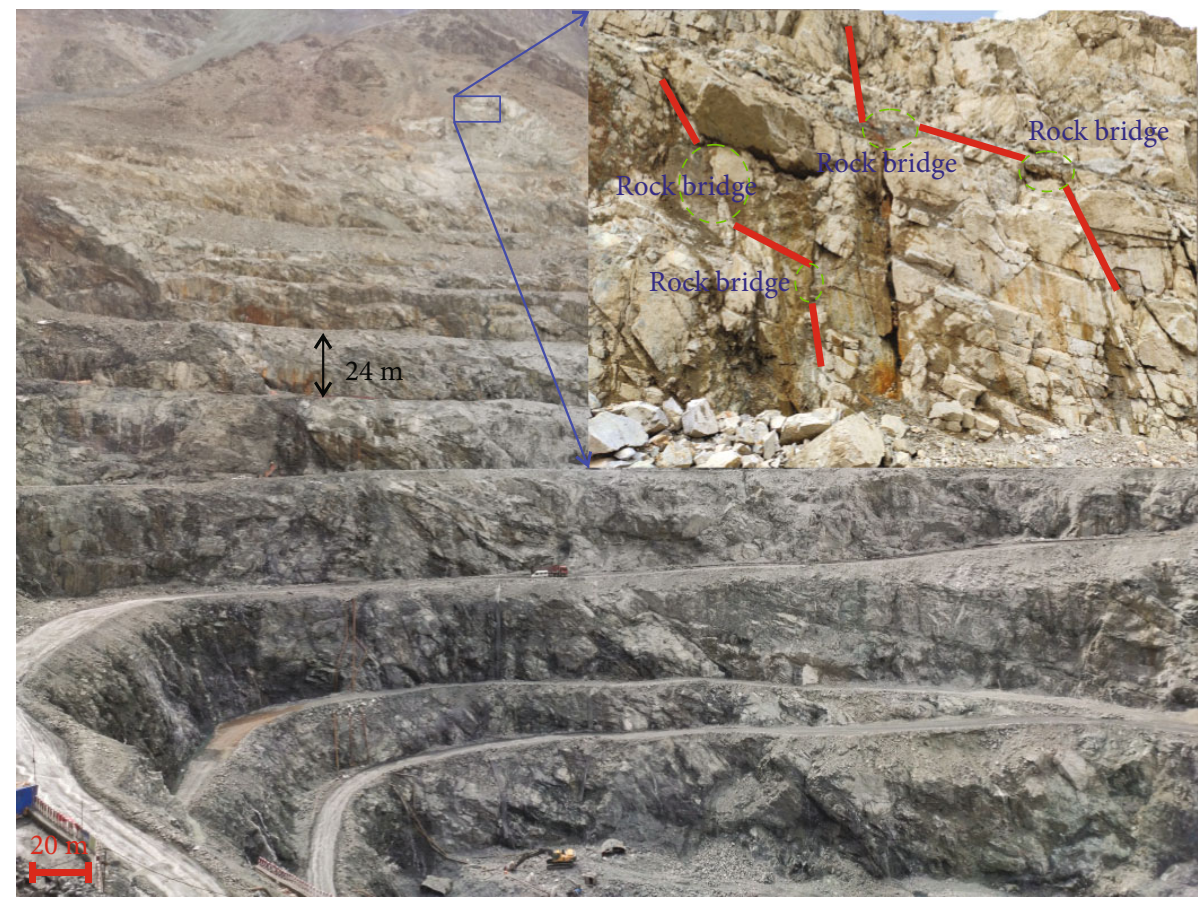

FIGURE 2: Photo of the western open pit slope, plenty of locking structural rock mass develop in the slope, the rock bridge is often named as "locking segment".

systematically studied, the flaw geometry, orientation, toughness, and numbers in the rock impact the overall strength and crack coalescence pattern [18-21]. To better understand the mechanical behaviors of fractured rock mass, substantial experimental efforts have been devoted to investigate the crack initiation, propagation, and coalescence of the flawed rock or rock-like materials under room temperature and compression $[15,21,22,24]$. For rock mass in cold regions, repeated F-T actions on the fractured rock is totally different for rock mass in room temperature. The effects of water/ice phase transformation on crack and frost cracking on rock have not been well studied. The accumulated damage and even the frost heaving cracks generated by F-T cycles may influence the crack propagation paths, the failure mode, and the rock strength. Therefore, rock samples containing flaws under F-T cycle and compressions have drawn deep attentions recently. Huang et al. [25] studied the shear strength characteristics of joints in three types of rock and revealed the influences of F-T on the strength parameters. Huang et al. [26] proposed a coupled thermohydromechanical model to study the frost heaving strain in preexisting flaw, and the influences of temperature and pore water/ice pressure on frost heaving strain have been studied. Huang et al. [27] conducted laboratory testing on rock-like material containing a single flaw under F-T and uniaxial compression, the crack propagation characteristics, and the frost-heaving cracking behavior were studied. Lu et al. [28] conducted a triaxial compression test on sandstone containing a single flaw subjected to F-T treatment, they considered the influences of confining pressure, F-T action, and loading on the 

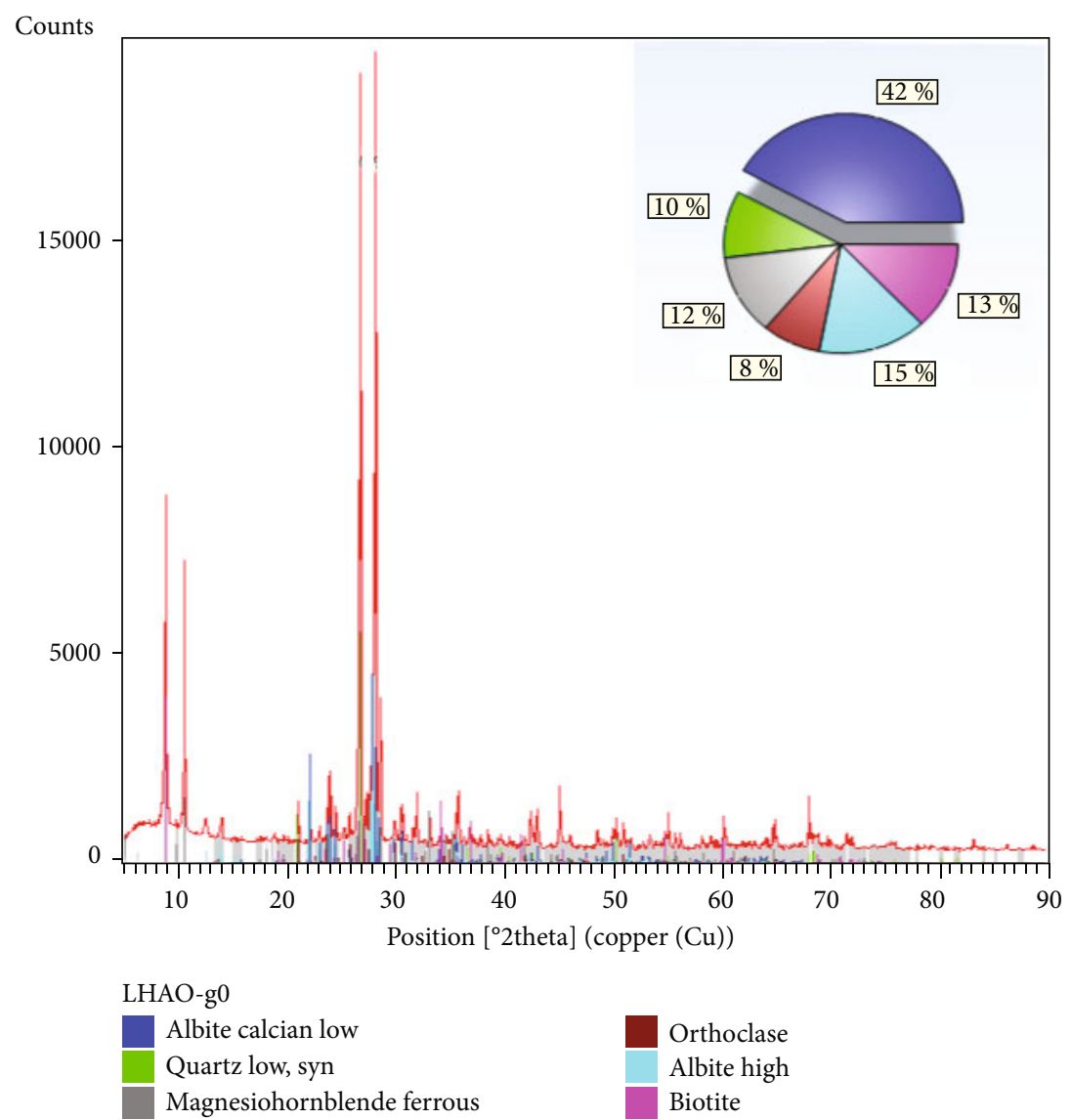

FIGURE 3: XRD analysis of the mineral composition of the rock power before F-T treatment.

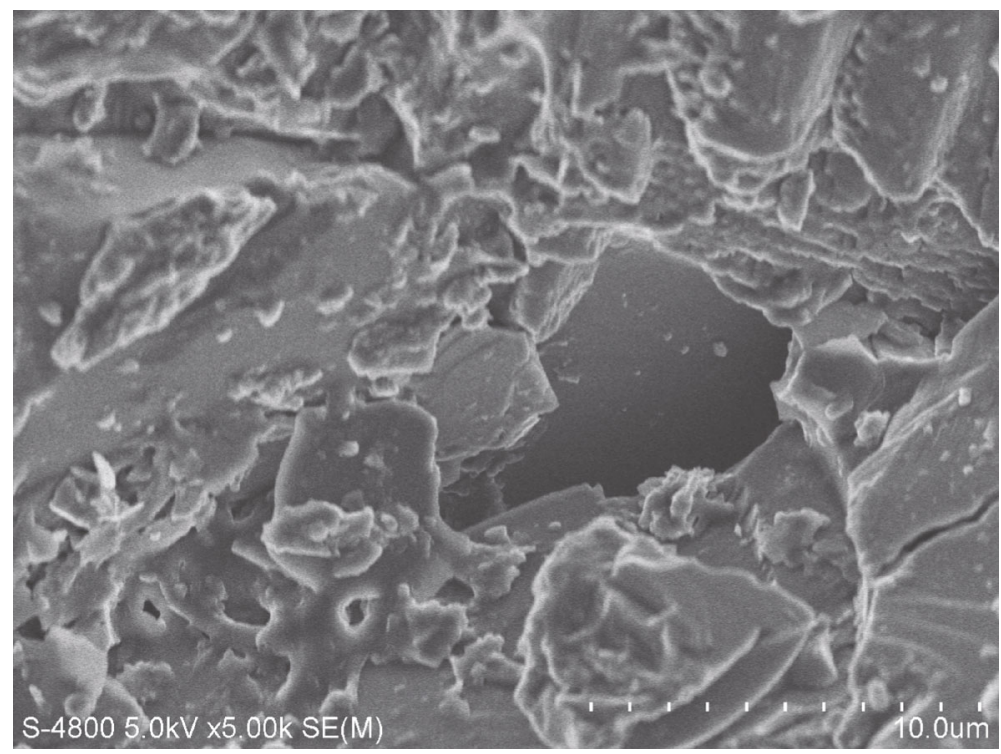

FIgURE 4: SEM results for granite with a magnification of 5000x before F-T treatment.

deterioration of rock mechanical properties and established a damage constitutive model to describe the damage of rock. Zhou et al. [29] studied the effect of F-T cycles in the cracking behavior of sandstone containing two unparallel flaws under uniaxial compression. In his studies, during sample deformation, the cracking process was recorded by a high-speed digital video camera, and crack coalescence patterns were observed in the experiment. The above investigations proved 

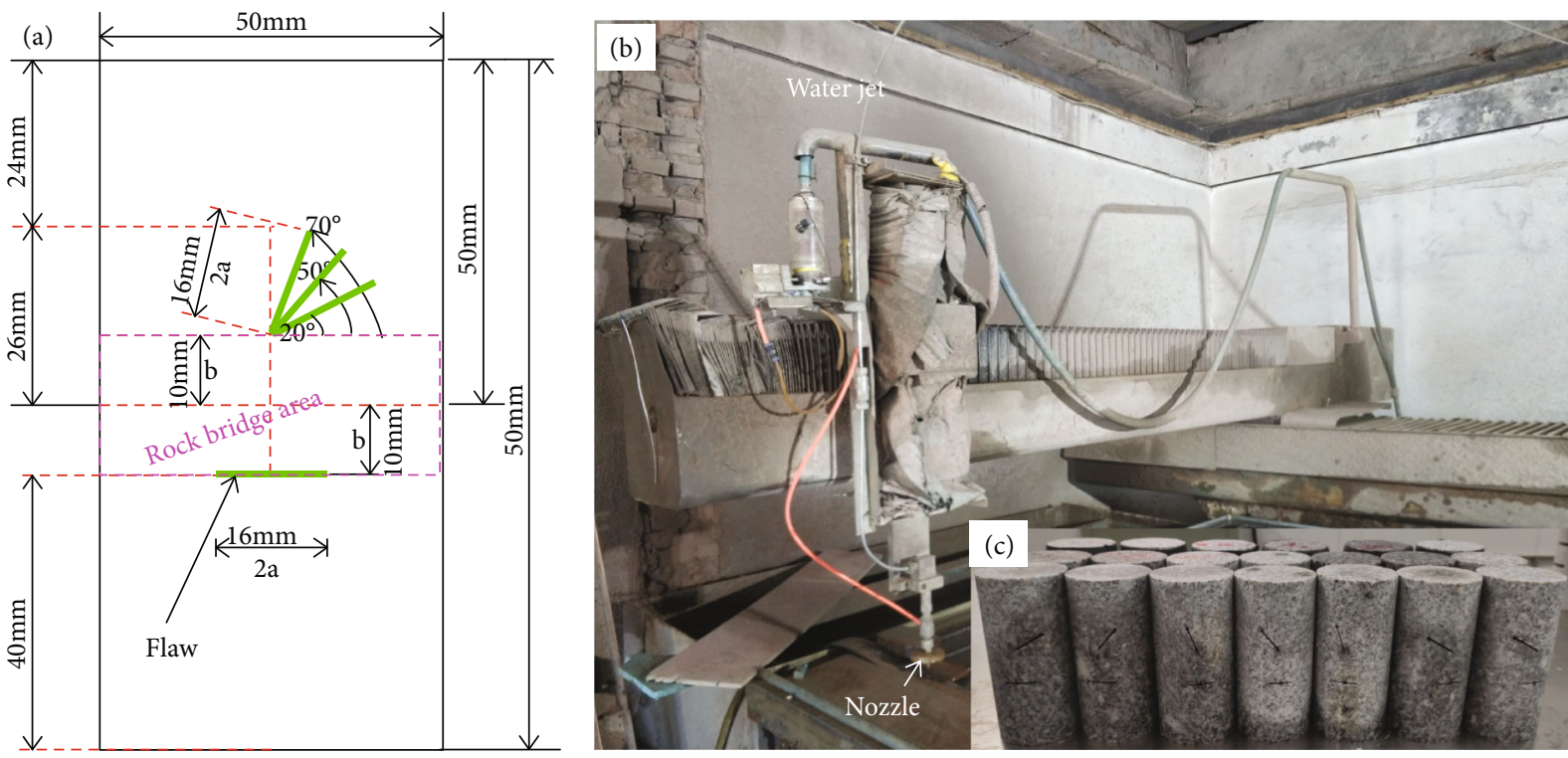

FIGURE 5: Preparation of the granite samples containing two flaws. (a) Scheme of the preparation project. (b) A water-jet system used to produce the flaws with its aperture of $1 \mathrm{~mm}$. (c) Samples used to conduct the experiments.

TABLE 1: Summarization of the basic physical and mechanical parameters of granite after F-T treatment.

\begin{tabular}{|c|c|c|c|c|c|c|c|}
\hline $\begin{array}{l}\text { Number of } \\
\text { F-T cycles }\end{array}$ & $\begin{array}{l}\text { Sample } \\
\text { ID }\end{array}$ & $\begin{array}{c}\text { Flaw inclination } \\
\text { angle }\left(^{\circ}\right)\end{array}$ & $\begin{array}{c}L \times d \\
(\mathrm{~mm} \times \mathrm{mm})\end{array}$ & $\begin{array}{l}\text { Mass } \\
(\mathrm{g})\end{array}$ & $\begin{array}{l}\text { Density } \\
\left(\mathrm{g} / \mathrm{cm}^{3}\right)\end{array}$ & Peak strength $(\mathrm{MPa})$ & P-wave velocity \\
\hline \multirow{6}{*}{$0 \mathrm{~F}-\mathrm{T}$} & G0-20-1 & 20 & $99.98 \times 50.37$ & 546.1 & 2.742 & 55.47 & 4456 \\
\hline & G0-20-2 & 20 & $100.03 \times 50.35$ & 545.6 & 2.741 & 56.21 & 4598 \\
\hline & G0-50-1 & 50 & $100.28 \times 50.60$ & 546.6 & 2.712 & 78.16 & 4473 \\
\hline & G0-50-2 & 50 & $100.01 \times 50.33$ & 545.4 & 2.743 & 75.65 & 4435 \\
\hline & G0-70-1 & 70 & $100.34 \times 50.36$ & 550.3 & 2.755 & 86.08 & 4456 \\
\hline & G0-70-2 & 70 & $100.08 \times 49.68$ & 545.1 & 2.811 & 84.87 & 4402 \\
\hline \multirow{6}{*}{$20 \mathrm{~F}-\mathrm{T}$} & G20-20-1 & 20 & $100.22 \times 49.45$ & 540.6 & 2.810 & 42.27 & 4210 \\
\hline & G20-20-2 & 20 & $100.06 \times 49.87$ & 540.3 & 2.766 & 44.45 & 4205 \\
\hline & G20-50-1 & 50 & $99.90 \times 49.48$ & 542.8 & 2.827 & 52.84 & 4289 \\
\hline & G20-50-2 & 50 & $100.01 \times 49.66$ & 540.6 & 2.792 & 51.25 & 4242 \\
\hline & G20-70-1 & 70 & $100.15 \times 49.38$ & 543.8 & 2.837 & 64.32 & 4198 \\
\hline & G20-70-2 & 70 & $100.15 \times 49.91$ & 543.5 & 2.775 & 67.09 & 4202 \\
\hline \multirow{6}{*}{$50 \mathrm{~F}-\mathrm{T}$} & G50-20-1 & 20 & $100.12 \times 50.03$ & 536.4 & 2.727 & 44.34 & 4032 \\
\hline & G50-20-2 & 20 & $100.75 \times 49.28$ & 538.1 & 2.802 & 46.87 & 4112 \\
\hline & G50-50-1 & 50 & $99.90 \times 49.55$ & 534.8 & 2.778 & 46.60 & 4065 \\
\hline & G50-50-2 & 50 & $100.11 \times 49.19$ & 534.2 & 2.809 & 47.24 & 4165 \\
\hline & G50-70-1 & 70 & $100.07 \times 49.82$ & 533.4 & 2.736 & 55.89 & 4034 \\
\hline & G50-70-2 & 70 & $100.05 \times 49.45$ & 531.6 & 2.768 & 58.41 & 4087 \\
\hline \multirow{6}{*}{$100 \mathrm{~F}-\mathrm{T}$} & G100-20-1 & 20 & $99.91 \times 50.44$ & 530.7 & 2.660 & 28.15 & 3854 \\
\hline & G100-20-2 & 20 & $100.01 \times 50.37$ & 530.8 & 2.665 & 26.25 & 3812 \\
\hline & G100-50-1 & 50 & $100.28 \times 50.45$ & 527.4 & 2.632 & 35.21 & 3902 \\
\hline & G100-50-2 & 50 & $100.01 \times 50.67$ & 526.2 & 2.611 & 37.45 & 3785 \\
\hline & G100-70-1 & 70 & $100.34 \times 50.21$ & 529.5 & 2.667 & 41.35 & 3854 \\
\hline & G100-70-2 & 70 & $100.54 \times 49.66$ & 530.3 & 2.725 & 39.78 & 3845 \\
\hline
\end{tabular}




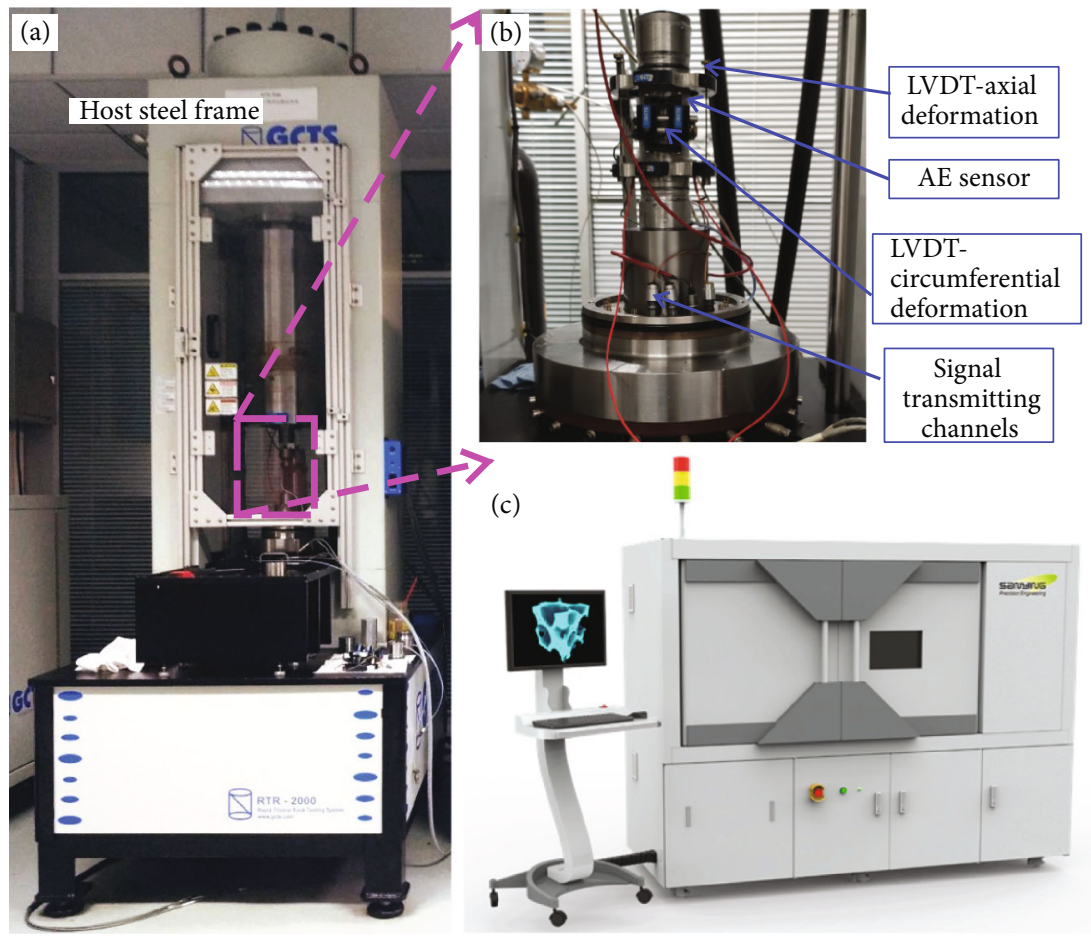

FIGURE 6: The experimental devices used in this work. (a) The rock mechanics machine. (b) The LVDT systems used to measure the axial and lateral deformation. (c) The $450 \mathrm{kV}$ industrial CT system used to obtain the crack pattern of marble.

the effects of F-T damage on the crack coalescence pattern of rock, which is different from rock cracking at room temperature.

Although attempts have been done to reveal the influence of F-T treatment on the strength and crack coalescence, most of the studies are focused on macroscopic stress-strain responses, where mapping of the internal strain filed is typically only observed after failure, for example, macroscopic crack pattern descriptions. The internal crack pattern for fractured rock subjected to F-T cycles and compression is hard to be detected. Thus, the basic purpose of this work is to reveal the crack pattern at the rock bridge area by using macroscopic descriptions combined with posttest CT scanning. The investigations are conducted for rock samples containing two unparallel flaws, in order to study the effect of F-T treatment on crack fatigue damage and the associated rock failure characteristics.

\section{Materials and Method}

2.1. Geological Settings of Study Area. The mining area is $123 \mathrm{~km}$ away from the Hejing County in the direction of $327^{\circ}$, the straight-line distance is $84 \mathrm{~km}$ away from Baluntai town of Hejing County, as shown in Figure 1. The administrative division is under the jurisdiction of Hejing County of Bayingolin Mongolian autonomous prefecture. Its central geographic coordinates are E $85^{\circ} 33^{\prime} 35^{\prime \prime}, \mathrm{N} 43^{\circ} 14^{\prime} 57^{\prime \prime}$. The mining area is located near the main ridge of Tianshan mountain on the north slope of Boluo Huoluo mountain. The mountain trend is nearly east-west, and the overall terrain is high in the south and low in the north, with an altitude of 3,160 4,575 m, and a relative altitude of 700 1000 $\mathrm{m}$. The orebody is located at an altitude of $3450 \sim 3723 \mathrm{~m}$.

According to the tectonic zoning map of the Xinjiang Uygur Autonomous Region, the preparation iron mine is located in the afulale-ishkilic late Paleozoic rift belt of the Yili microplate of the Tarim plate. In the north, the igshagezi guole-guoler fault is bounded by the borokanu early Paleozoic island-arc backarc belt, and in the south, the dunde guoldaban fault is bounded by the harlek-barontai early Paleozoic gully arc belt. The rift belt is a wedge-shaped strip with wide west and narrow east. The strata from old to new in the region includes the paleoproterozoic narati group $(\mathrm{Pt} 1 \mathrm{~N})$, upper devonian arken limestone segment (D3als), lower carboniferous dahalanjunshan formation (C1d), lower-middle Jurassic shuixigou formation (J1-2s), and the quaternary (Q).

2.2. Description of Shale Material. The rock was obtained from the Beizhan open pit slope located at the Xinjiang province, northwest of China (Figure 2). The lithology of the rock is granite, which is distributed at the west boundary of the open pit slope, as shown in Figure 1. There are three sets of joints on the west slope, plenty of joints are intermittent, that form a locking section on the rock mass, this kind of structural body has a strong effect on the stability of the rock slope, as shown in Figure 2. The rock cores were drilled and prepared in a cylindrical shape with a diameter $(D)$ of $50 \mathrm{~mm}$ and a height $(H)$ of $100 \mathrm{~mm}$ according to the ISRM-suggested methods. Both ends of the samples were polished to ensure the error of unevenness is less than $0.05 \mathrm{~mm}$ and parallelism of both ends is less than 


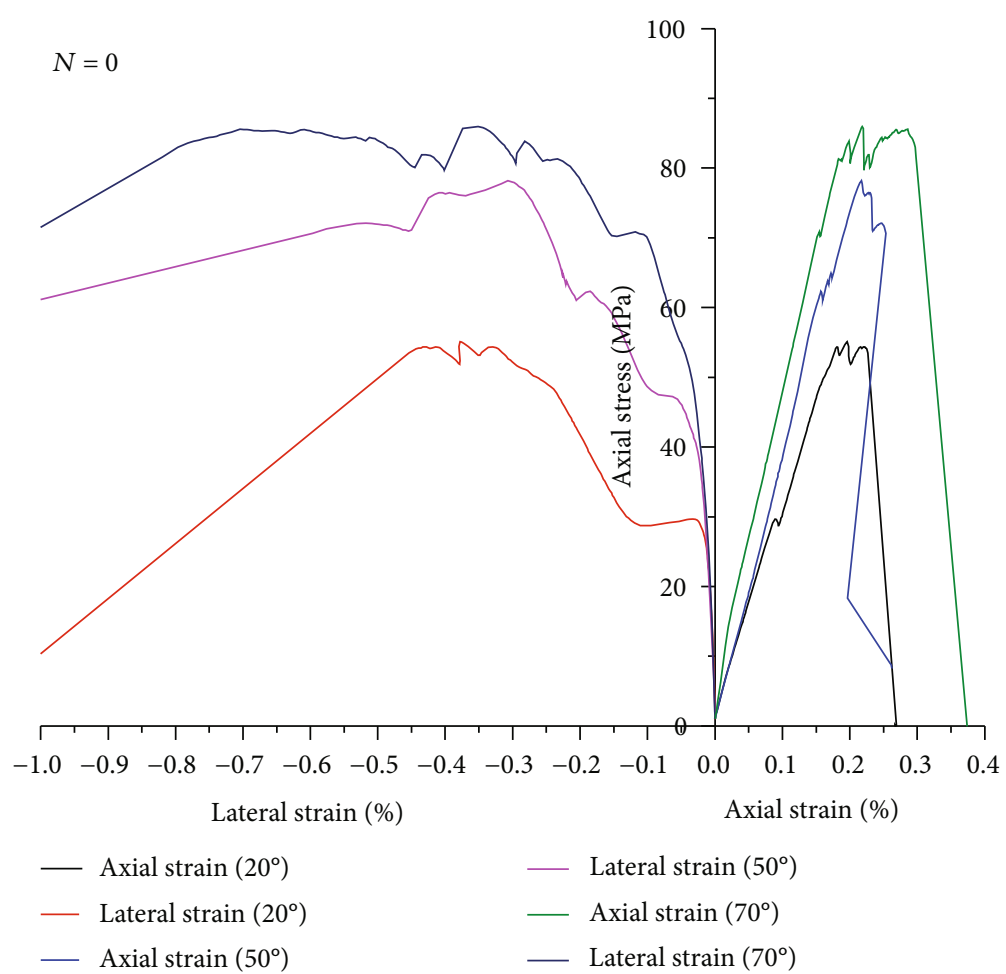

(a) $N=0$

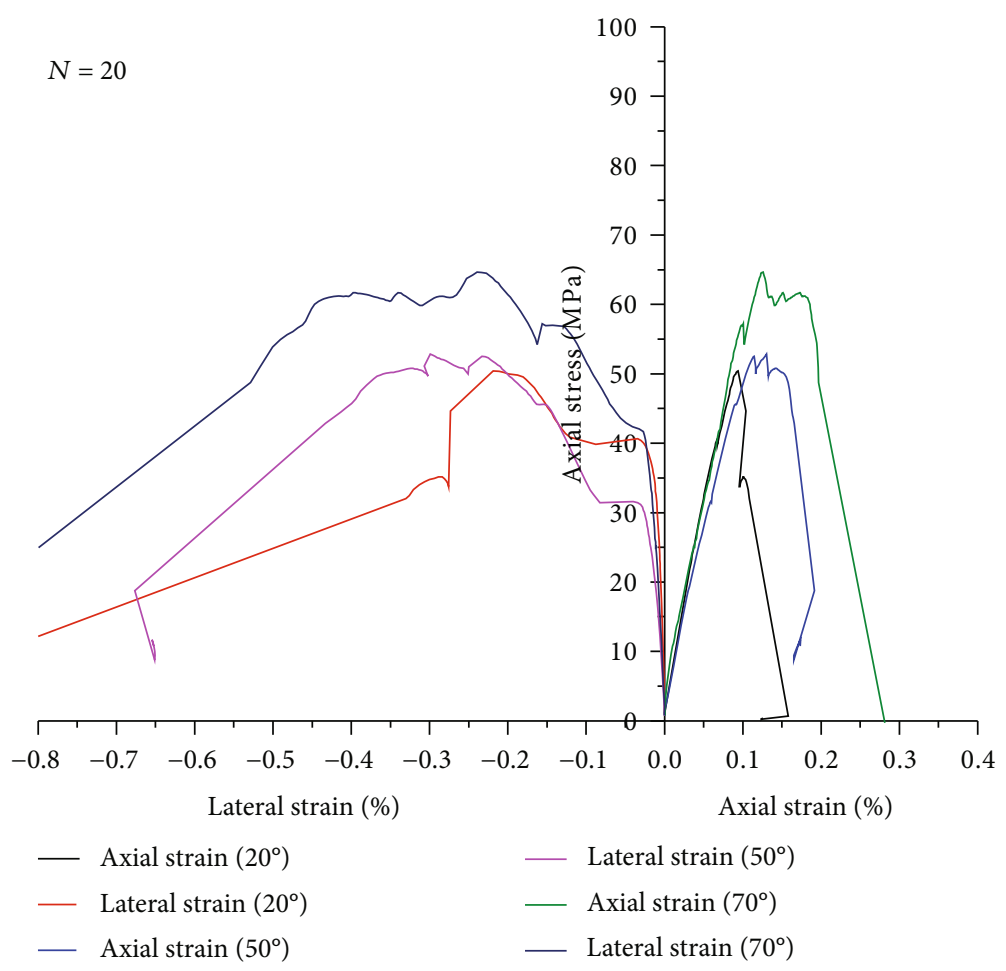

(b) $N=20$

Figure 7: Continued. 


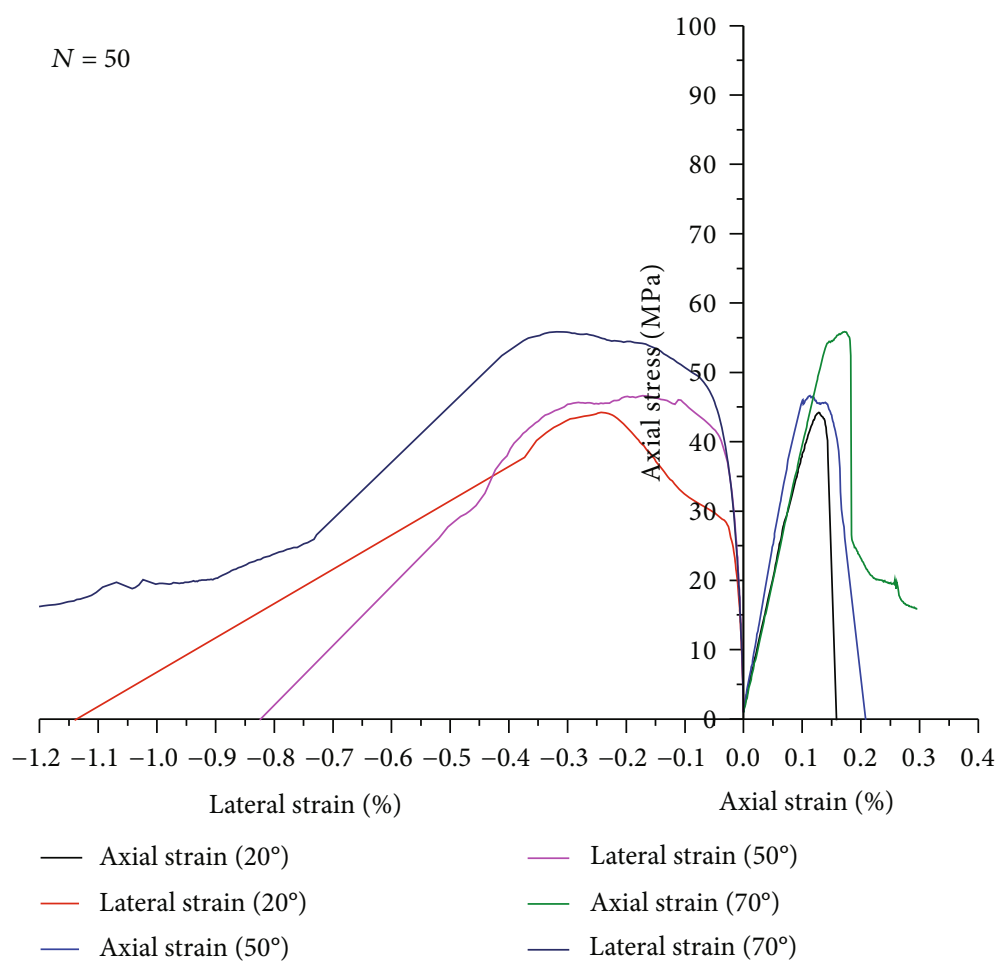

(c) $N=50$

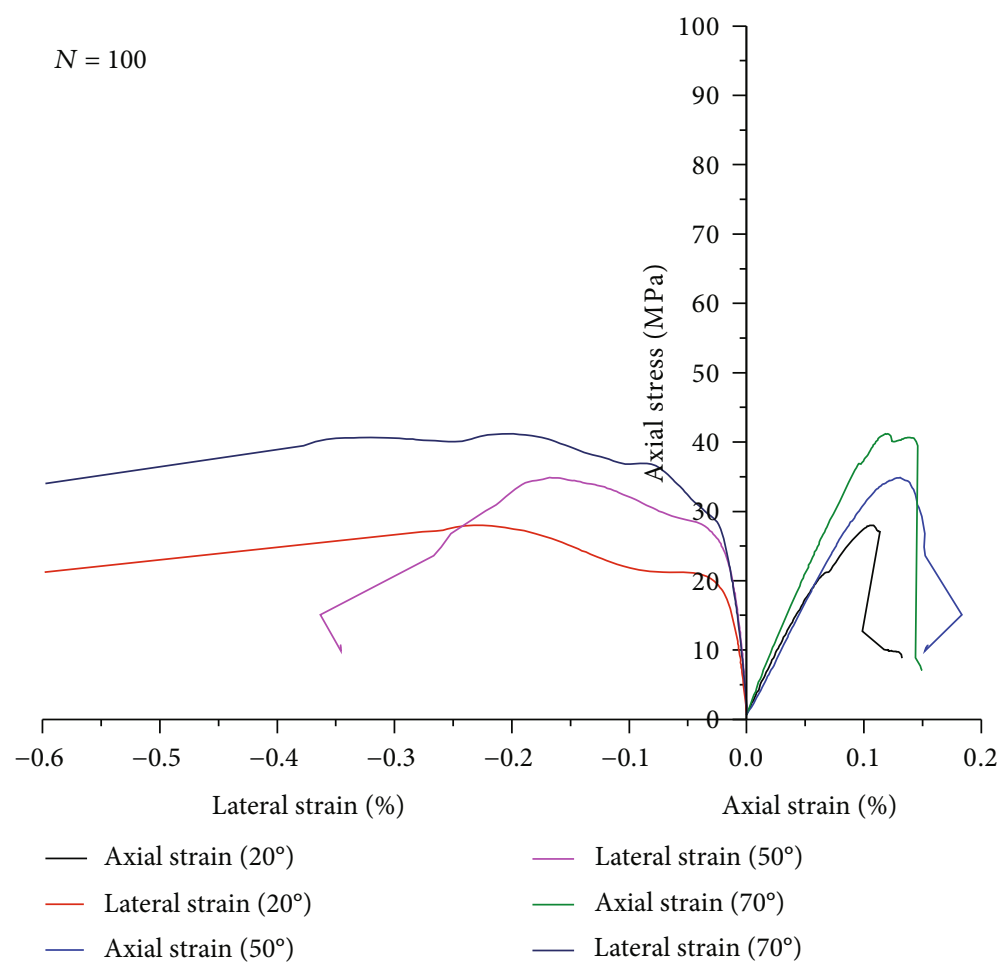

(d) $N=100$

Figure 7: The typical axial and lateral stress-strain curves for the samples containing two flaws. (a-d) The number of F-T cycles is 0 , 20, 50, and 70 , respectively.

$0.1 \mathrm{~mm}$. From the results of X-ray powder diffraction (XRD) in Figure 3, the granite was mainly composed of albite (75\%), quartz (10\%), magnesiohornblende (12\%), orthoclase (8\%), and biotite (13\%) minerals. By SEM imaging analysis
(Figure 4), it can be seen that some microcracks develop at the interfaces of minerals; in addition, some large pores and many small pores can be observed during the formation of granite. 


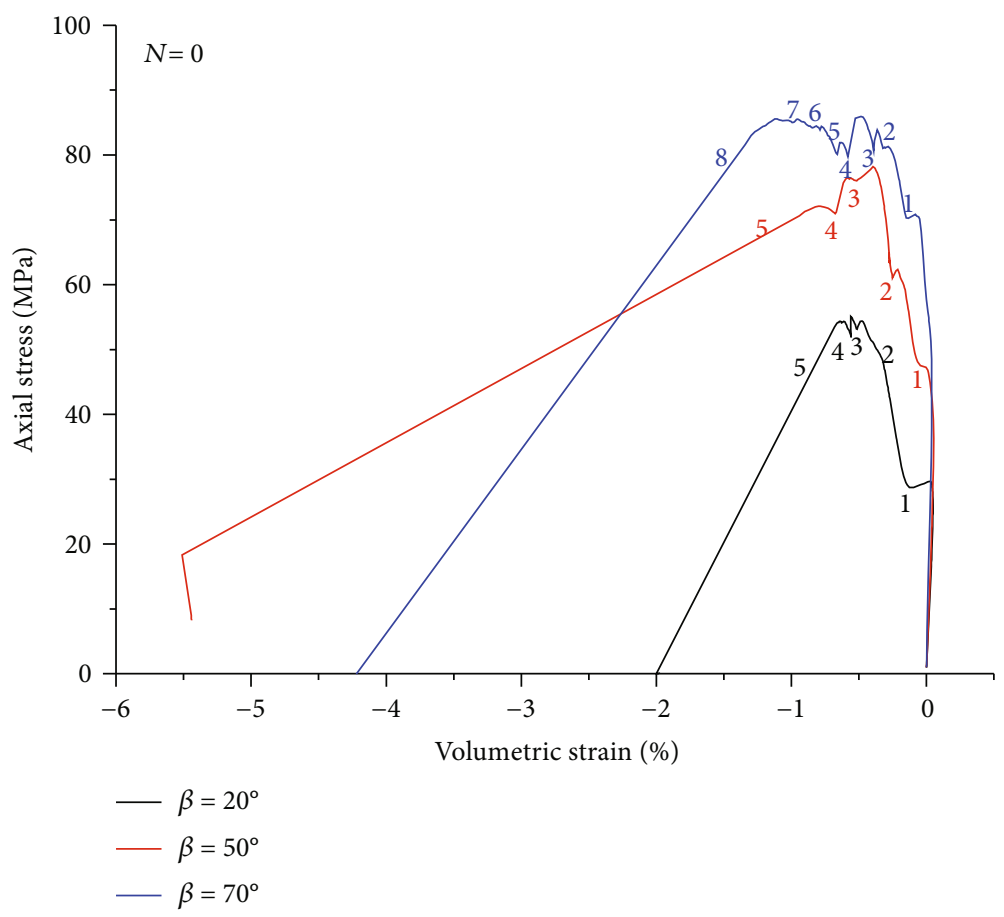

(a) $N=0$

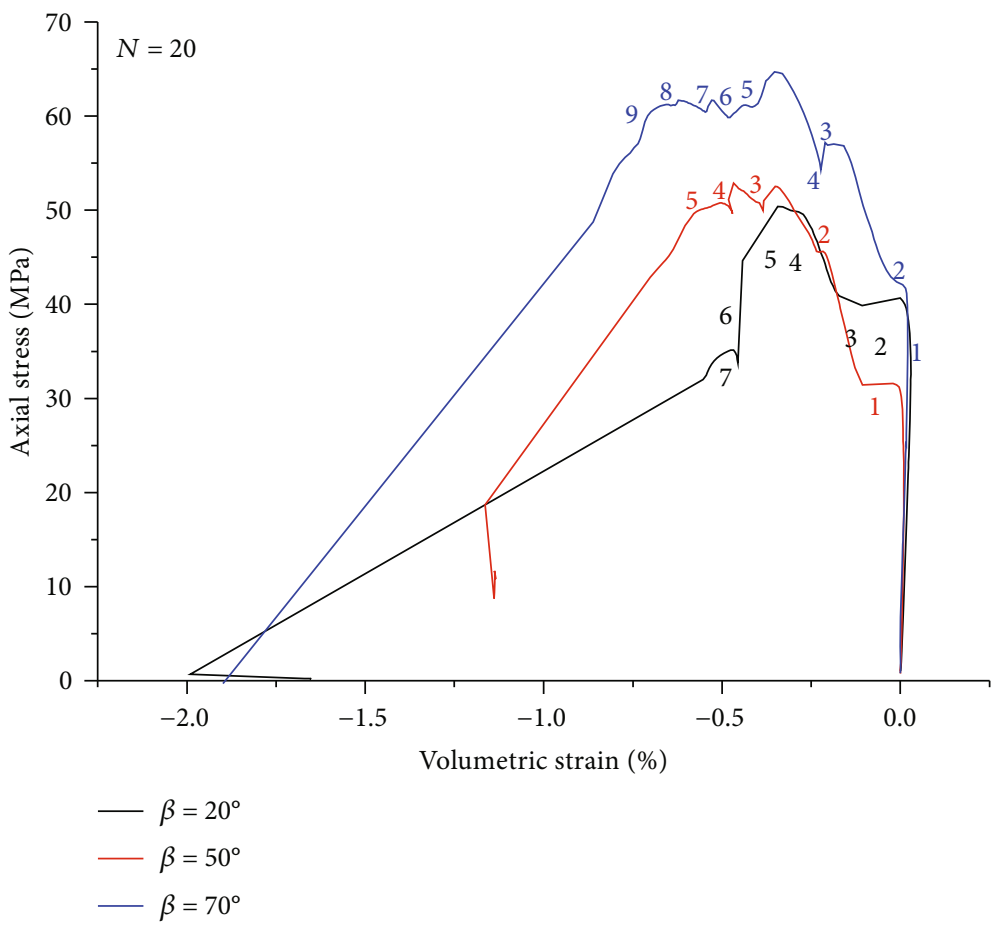

(b) $N=20$

Figure 8: Continued. 


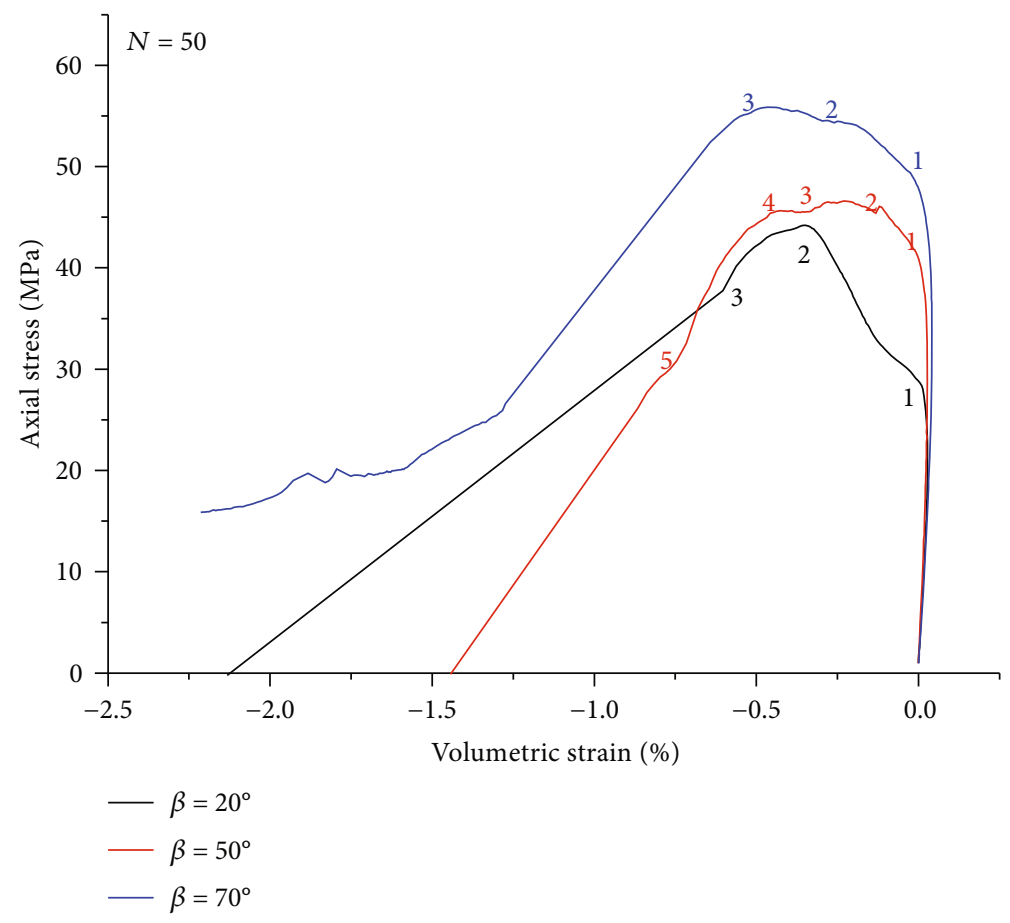

(c) $N=50$

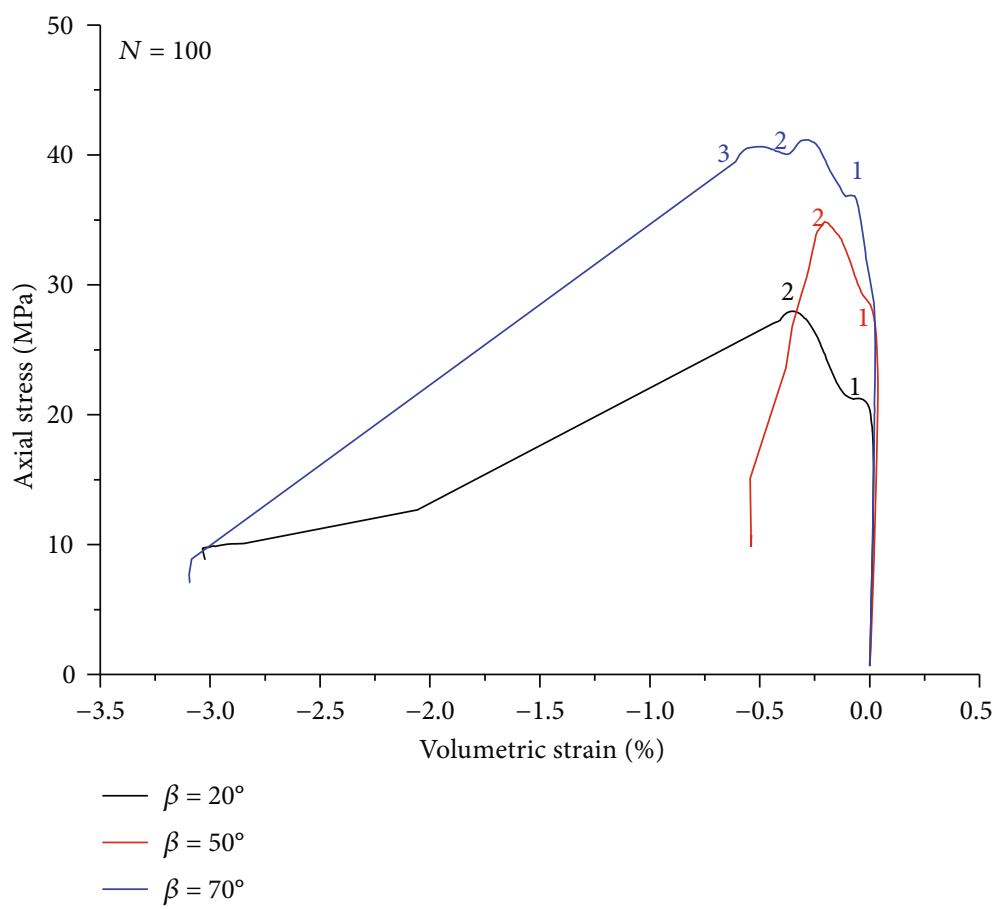

(d) $N=100$

FIGURE 8: The typical volumetric stress-strain curves for the samples containing two flaws. (a-d) The number of F-T cycles is 0 , 20, 50, and 70, respectively.

In order to simulate the locking effect of rock mass, double-flawed samples were prepared. The flaw geometry in a double-flawed sample was a combination of an upper inclined flaw and a horizontal flaw with a length (2a) of $12 \mathrm{~mm}$. The inclined flaw had an approach angle $(\beta)$ of $20^{\circ}$, $50^{\circ}$, and $70^{\circ}$. The locking section length (i.e., rock bridge length) as defined in Figure 5(a) was set to be $12 \mathrm{~mm}$ in order to allow the crack coalescence in the locking section. To generate the two flaws in each rock sample, a water-jet system instead of a diamond saw was used to make the flaws 


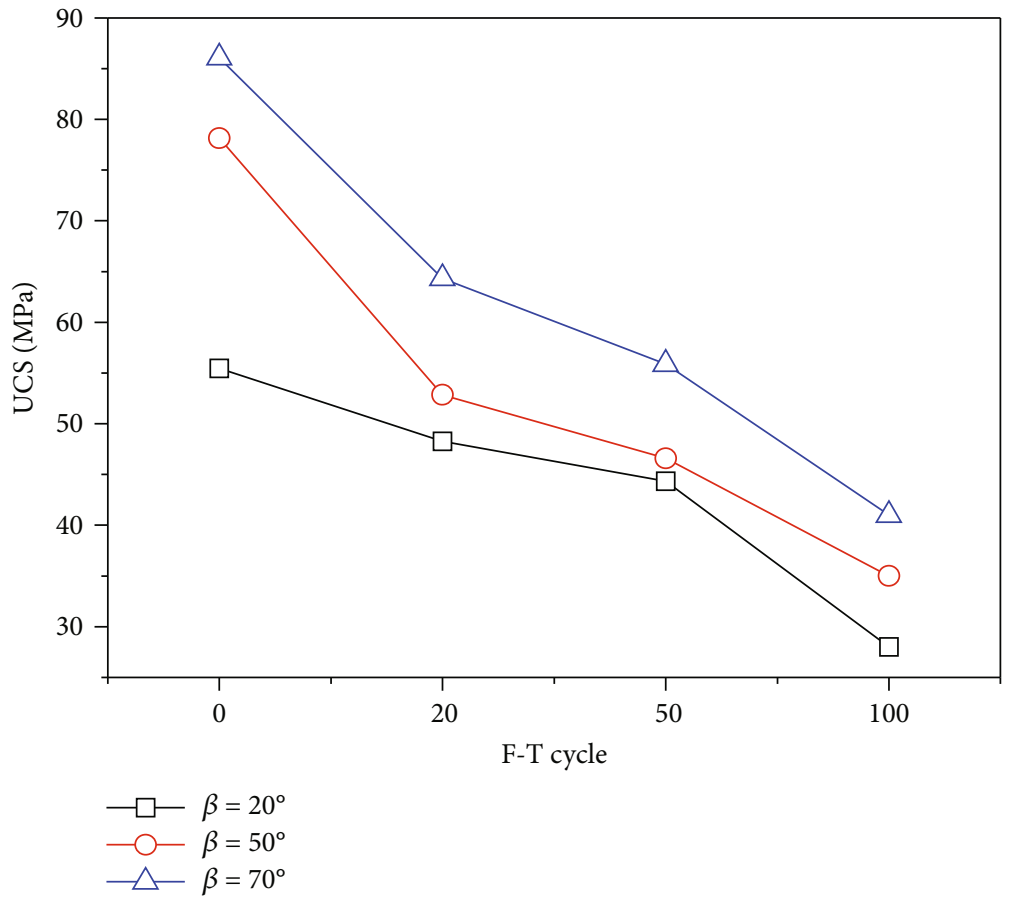

(a)

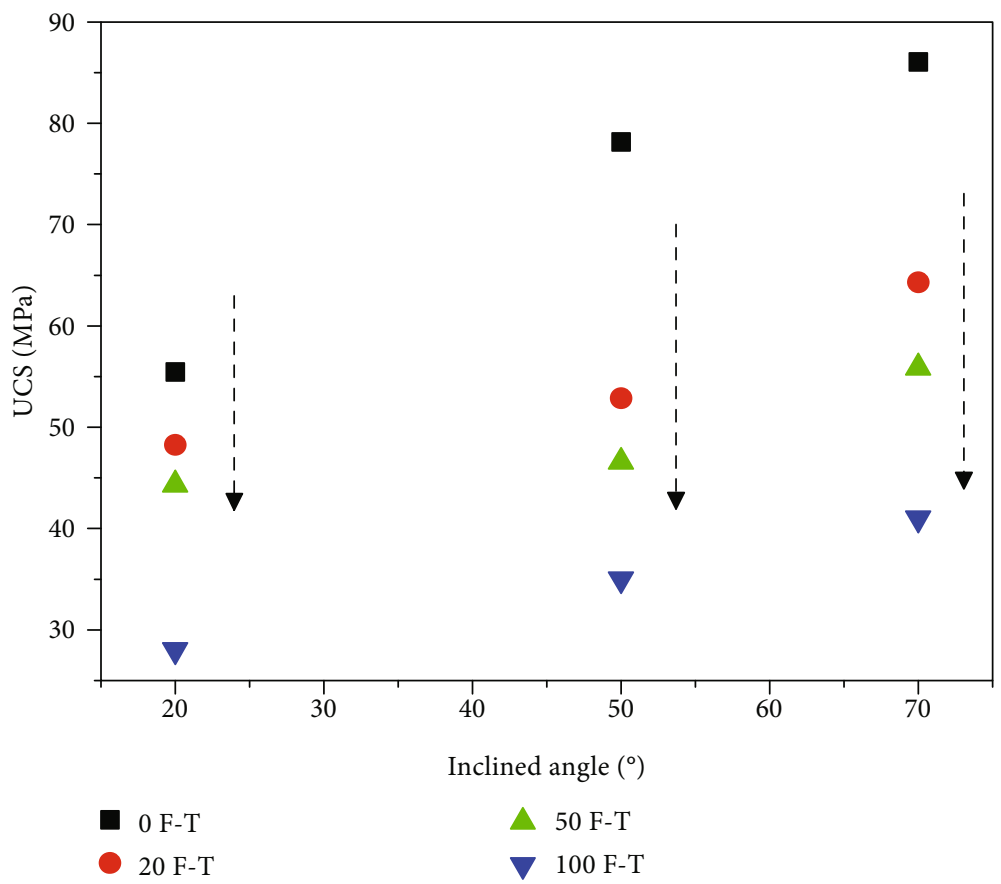

(b)

FIGURE 9: Uniaxial compressive strength (UCS) of the tested granite samples. (a) Changes of UCS with freeze-thaw cycles. (b) Changes of UCS with the approach angle defined in Figure 5(a).

(Figure 5(b)). High-pressure water mixed with garnet abrasive ejected from a $0.75 \mathrm{~mm}$ diameter nozzle produced a flaw with its aperture of $1 \mathrm{~mm}$.

2.3. Freeze-Thaw Treatment. The samples were conducted vacuum saturation for 24 hours before the F-T treatment. A JS-DW-40 ultra-low temperature freezer was used to realize
F-T cycles. According to the temperature changes of the Beizhan mining area, in the F-T treatment, saturated samples were placed into the F-T machine and conditioned $-40^{\circ} \mathrm{C}$ for $12 \mathrm{~h}$, and then, the samples were taken out of the freezer and placed into the water at $20^{\circ} \mathrm{C}$, where they were allowed to thaw for $8 \mathrm{~h}$. Under the freeze condition, the rock bridge (locking segment) was wrapped with a cotton cloth in order 
TABLE 2: Crack propagation and coalescence for the samples with an inclination flaw of $20^{\circ}$.

\begin{tabular}{|c|c|c|c|c|}
\hline$\beta=20^{\circ}$ & $N=0$ & $N=20$ & $N=50$ & $N=100$ \\
\hline \multicolumn{5}{|l|}{ Failure morphology } \\
\hline $\begin{array}{l}\text { Crack coalescence } \\
\text { patterns }\end{array}$ & $\begin{array}{l}\text { (i) Tensile cracks initiated } \\
\text { from the flaw tips and } \\
\text { almost parallel to the } \\
\text { major stress direction } \\
\text { (ii) failure by only tensile or } \\
\text { tensile+shear cracks } \\
\text { (iii) crack propagation from } \\
\text { the left part of the } \\
\text { inclined flaw to the } \\
\text { middle of the } \\
\text { horizontal flaw } \\
\text { (iv) plenty of cracks exist at } \\
\text { the rock bridge }\end{array}$ & $\begin{array}{l}\text { (i) Crack propagation } \\
\text { from the left of the } \\
\text { inclined flaw and } \\
\text { propagation to the } \\
\text { middle of the } \\
\text { horizontal flaw } \\
\text { (ii) crack propagation from } \\
\text { the right tip of the } \\
\text { horizontal flaw to the } \\
\text { middle of the inclined } \\
\text { flaw } \\
\text { (iii) tensile failure occurs at } \\
\text { the rock bridge and } \\
\text { failure }\end{array}$ & $\begin{array}{l}\text { (i) Crack propagation } \\
\text { from the middle of the } \\
\text { inclined flaw to right } \\
\text { tip of the horizontal } \\
\text { flaw, multiple tensile } \\
\text { cracks initiated from } \\
\text { the left of the } \\
\text { horizontal flaw } \\
\text { (ii) shear crack initiated } \\
\text { from the left tip of the } \\
\text { inclined flaw } \\
\text { (iii) failure by only tensile } \\
\text { crack } \\
\text { (iv) two cracks exist at the } \\
\text { rock bridge }\end{array}$ & $\begin{array}{l}\text { (i) Crack propagation } \\
\text { from the left of the } \\
\text { inclined flaw to the } \\
\text { middle of the } \\
\text { horizontal flaw } \\
\text { (ii) failure by only tensile } \\
\text { crack } \\
\text { (iii) crack propagation from } \\
\text { the right of the } \\
\text { horizontal flaw to the } \\
\text { middle of the inclined } \\
\text { flaw } \\
\text { (iv) number of cracks at the } \\
\text { rock bridge gets to the } \\
\text { minimum }\end{array}$ \\
\hline
\end{tabular}

to ensure the full-freeze state. The two flaws were ensured to be ice-filled, in order that the frost heave force can act on the flaws. Here, four groups of samples containing flaws were treated with F-T cycles of 0 (no F-T treatment), 20, 50, and 100 , respectively. Detailed descriptions of the basic physical and mechanical characteristics of the tested samples are listed in Table 1.

2.4. Testing Device. The uniaxial compression experiments were conducted on a GCTS RTR 2000 rock mechanics testing system with a constant loading rate of $0.06 \mathrm{~mm} / \mathrm{min}$, as shown in Figure 6(a). During the test, rock axial and lateral strains are simultaneously measured by two axial sensors and one circumferential sensor (LVDT system) (Figure 6(b)). A center computer is used to record the strength and deformation information, which includes axial strain, axial stress, and lateral strain at the same sampling frequency. In this study, two samples were prepared for each experimental group.

After the uniaxial tests, X-ray CT scanning for each sample was conducted in order to obtain the failure CT images inside the sample. In this study, a high-resolution CT machine of nanoVoxel-3000 with a source voltage of $160 \mathrm{kV}$ and source current of $200 \mathrm{~A}$ was used for imaging, as shown in Figure 6(c). For a sample, five CT images were obtained from the top, middle, and bottom of the marble sample, the corresponding positions are 58, 54, 50, 46, and $42 \mathrm{~mm}$, respectively. Based on the CT images, the internal failure morphology of the marble samples can be well revealed. The testing device used in this work is shown in Figure 6.

\section{Experimental Results and Analyses}

3.1. Representative Stress-Strain Curves. For the granite samples containing two unparallel flaws subjected to different F-T cycles, uniaxial compression tests were done to reveal the stress-strain responses. Figure 7 plots the axial and lateral stress-strain curves for the samples with different approach angles subjected to $0,20,50$, and $100 \mathrm{~F}-\mathrm{T}$ cycles. No matter how many are the F-T cycle, the peak stress increases with the increasing approach angle. The peak stress is the minimum for the sample having a $20^{\circ}$ approach angle; it is the maximum for the sample having an approach angle of $70^{\circ}$. The overall deformation trend is that the stress-strain curves present fluctuation with increasing deformation. An obvious phenomenon of stress drop occurs with the stress growth before the peak stress. The stress drop points on the stressstrain curves indicate the initiation and propagation of cracks 
TABLE 3: Crack propagation and coalescence for the samples with an inclination flaw of $50^{\circ}$.

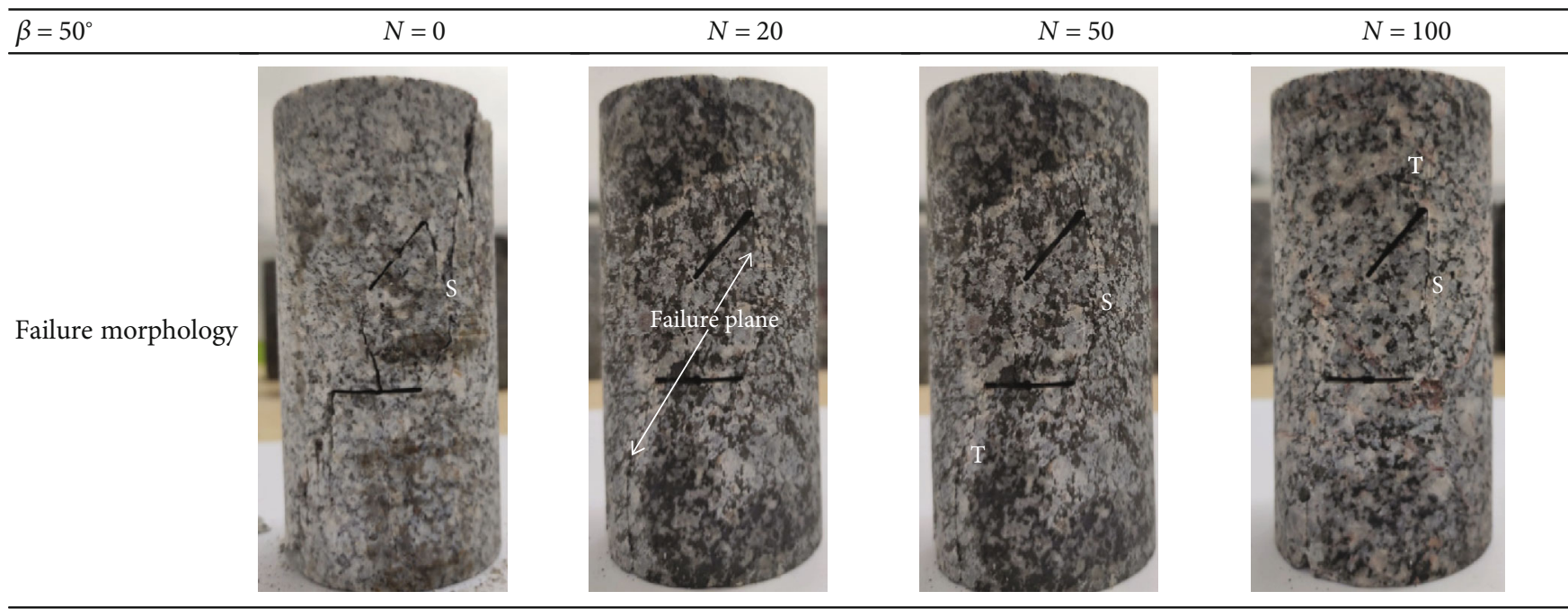

(i) Tensile cracks were initiated from the right tip of the inclined flaw, anticrack propagation to the right tip of horizontal crack

(ii) Tensile crack propagation from the middle of the horizontal flaw to the

Crack coalescence patterns (i) Tensile cracks were

(iii) Shear cracks were observed and induced failure

(iv) Flaw aperture thickness both decreases for the two flaws

(v) Many cracks develop at the rock bridge segment initiated from the left tip of the inclined flaw, and propagation to the middle of horizontal crack

(ii) Shear crack was initiated from the middle of the inclined crack and induced failure

(i) Failure only by tensile cracks

(ii) Tensile crack from the right tip of the inclined flaw and propagation to the right tip of horizontal crack

(iii) Tensile crack propagation from the left tip of the inclined flaw to the middle of the horizontal flaw

(ii) No cracks between the right tip of the inclined flaw and horizontal flaw

(iv) Number of cracks at the rock bridge decreases (iv) No decrease in flaw aperture thickness

(v) Crack at the rock bridge decreases (i) Tensile cracks were initiated from the left tip of the inclined flaw and propagation to the middle of horizontal crack, anticrack propagation to the right tip of inclined crack

(ii) Number of cracks at the rock bridge decreases sharply and it got to the minimum inside the granite samples. When a sudden failure occurs, crack initiates and the cracks continuously propagate when the energy accumulated to a certain level. After the peak stress, the sample fails abruptly and the stress-strain curve drops to zero quickly. From the morphology of the stressstrain curves, it can also be seen that the number of the stress drop points is large for samples subjected to 0 and 20 cycles. For the samples that are subjected to $100 \mathrm{~F}-\mathrm{T}$ cycles, the stress-strain curve grows smoothly, and no obvious stress drop point can be observed.

In order to well reflect the influence of axial and lateral deformation on the volumetric changes, the volumetric strain $\left(\varepsilon_{\mathrm{v}}\right)$ is calculated according to the axial strain $\left(\varepsilon_{1}\right)$ and lateral strain $\left(\varepsilon_{3}\right)$ as $\varepsilon_{\mathrm{v}}=\varepsilon_{1}-2 \varepsilon_{3}$. The volumetric strain reflects the combination effect of axial and lateral deformation. Figure 8 depicts the volumetric stress-strain curves for the samples subjected to different F-T cycles. The stress drop point can be observed clearly from the curves, and they are labeled as " $1,2,3, \ldots$ ”. It is clearly seen that the stress drop becomes weaker as the number of F-T cycle increases. In addition, it can be also seen that the volumetric strain increases with the increasing approach angle, and it is the maximum for the sample with an inclined angle of $70^{\circ}$.

3.2. UCS of the Tested Samples. The F-T effects on the deterioration of rock geomechanical properties include the frozenheave force induced by the phase transition of water; the increase of pores, voids, and microcracks; the variation of minerals by water-ice phase transition; and the dissolution of minerals. For the granite samples having preexisting flaws, the frost heaving force in the flaw was greater than the frost heaving pressure in the pore or voids; therefore, damage of the flaw caused by the F-T action was much more serious. The differential damage for the samples subjected to 0,20 , 50 , and $100 \mathrm{~F}-\mathrm{T}$ cycles will certainly lead to the different 
TABLE 4: Crack propagation and coalescence for the samples with an inclination flaw of $70^{\circ}$.

\begin{tabular}{|c|c|c|c|c|}
\hline$\beta=70^{\circ}$ & $N=0$ & $N=20$ & $N=50$ & $N=100$ \\
\hline \multicolumn{5}{|l|}{ Failure morphology } \\
\hline $\begin{array}{l}\text { Crack coalescence } \\
\text { patterns }\end{array}$ & $\begin{array}{l}\text { (i) Tensile crack was } \\
\text { initiated from the right } \\
\text { tip of the inclined flaw } \\
\text { (ii) No cracks between the } \\
\text { left tip of the inclined } \\
\text { flaw and the left tip of } \\
\text { the horizontal flaw } \\
\text { (iii) Shielding of the } \\
\text { horizontal flaw against } \\
\text { vertical stress } \\
\text { (iv) Plenty of tensile cracks } \\
\text { at the rock bridge } \\
\text { segment }\end{array}$ & $\begin{array}{l}\text { (i) Tensile cracks were } \\
\text { initiated from the right } \\
\text { tip of the inclined flaw, } \\
\text { one anticrack } \\
\text { propagation from the } \\
\text { left of the horizontal } \\
\text { crack } \\
\text { (ii) Two tensile cracks were } \\
\text { initiated from the left } \\
\text { tip of the horizontal } \\
\text { flaw } \\
\text { (iii) Cracks at the rock } \\
\text { bridge segment } \\
\text { decreases as F-T cycle } \\
\text { increases }\end{array}$ & $\begin{array}{l}\text { (i) Tensile cracks were } \\
\text { initiated from the left tip } \\
\text { of the inclined flaw and } \\
\text { propagated to the left of } \\
\text { the horizontal flaw, two } \\
\text { anti-cracks propagation } \\
\text { from the right of the } \\
\text { horizontal crack } \\
\text { (ii) Number of cracks at the } \\
\text { rock bridge segment } \\
\text { decreases }\end{array}$ & $\begin{array}{l}\text { (i) Tensile cracks were } \\
\text { initiated from the left } \\
\text { tip of inclined flaw and } \\
\text { propagated to the right } \\
\text { of the horizontal flaw } \\
\text { (ii) Tensile cracks were } \\
\text { imitated from the two } \\
\text { tips of the horizontal } \\
\text { flaw } \\
\text { (iii) Number of cracks at the } \\
\text { rock bridge gets to the } \\
\text { minimum }\end{array}$ \\
\hline
\end{tabular}

strength characteristics. Figure 9 plots the relationship between the UCS and F-T cycles. The UCS decreases with the increasing of F-T cycles. For a sample that is subjected to high F-T treatment, damage induced by the frost heaving force inside the flaws is most severe, and the strength of the sample is the minimum accordingly. In addition, the UCS is affected by the approach angle, and UCS is the largest for the samples having a $70^{\circ}$ approach angle.

3.3. Macroscopic Crack Pattern Descriptions. For samples with an approach angle $(\beta)$ of $20^{\circ}$, the crack coalescence pattern is obviously different from the sample subjected to different F-T treatment. For a sample without F-T treatment $(N=0)$, commonly observed coalescence crack was a crack from the left tip of the inclined flaw to the middle part of the horizontal flaw. If there is a failure by only tensile or a combination of tensile and shear cracking, the cracks in the rock bridge area is well developed, as shown in Table 2. Tables 2-4 summarize the macroscopic failure characteristics and crack pattern for flaw approach angles of $20^{\circ}, 50^{\circ}$, and $70^{\circ}$, respectively. Figure 10 shows sketches of the cracks with denoting crack types ( $\mathrm{T}$ for tensile crack and $\mathrm{S}$ for shear crack) and the cracking order.
In Figure 10(a), tensile cracks almost initiate from the left tip of the inclined angle and propagate to the horizontal flaw (T1 of G0-20, T1 of G20-20, and T1 of G100-20) for $N=0$, 20 , and 100 . For $N=50$, a shear crack was initiated from the left tip of the inclined flaw (S1 of G50-20). The crack number at the rock bridge area decreases with increasing F-T cycles.

In Figure $10(\mathrm{~b})$, the approach angle $(\beta)$ is $50^{\circ}$. Cracks were initiated from the left tip of the inclined flaw and propagate towards the horizontal flaw (T1 of G0-50, T1 of G20-50, and T1 of G100-50). Anticrack (the propagation direction is opposite to the convention) is observed for T5 of G0-50, and a large crack band is located at the right tip of the inclined flaw. For the horizontal flaw, cracks were initiated at the left tip and almost parallel to the major stress direction and multiple shear cracks were observed for $N=0$ sample. The crack density at the rock bridge area is the largest for the $N=0$ sample and smallest for the $N=100$ sample.

In Figure $10(\mathrm{c})$, the approach angle $(\beta)$ is $70^{\circ}$. For this sample with a high approach angle, anticracks are easily formed, and this kind of crack is consistent with the results of Huang et al. [18]. For $N=0$ sample, tensile crack was initiated from the right tip of the inclined flaw and no cracks 


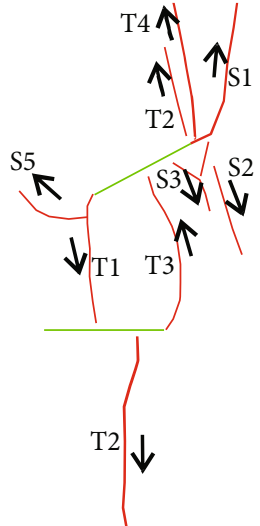

G0-20

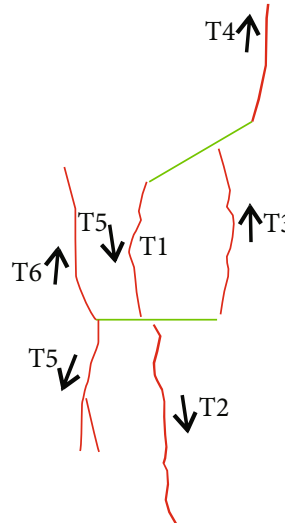

G20-20

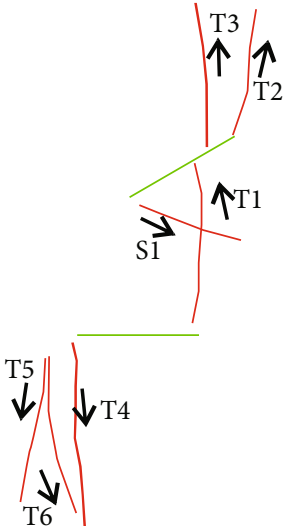

G50-20

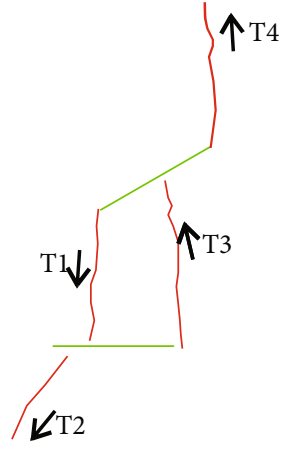

G100-20

(a)
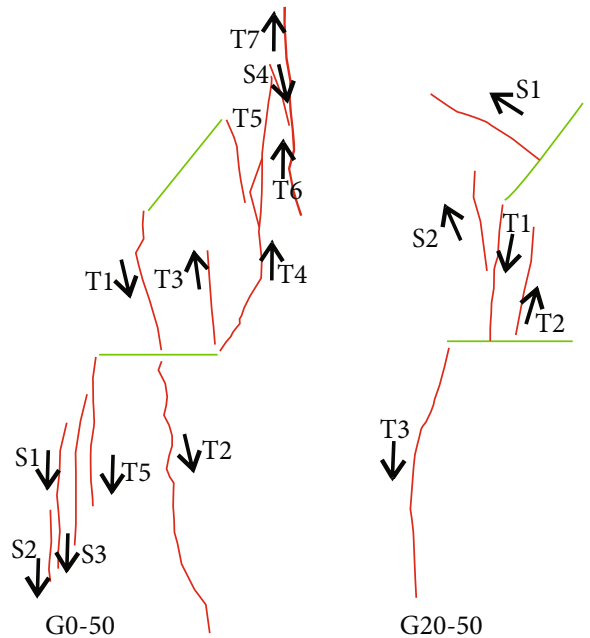

G20-50

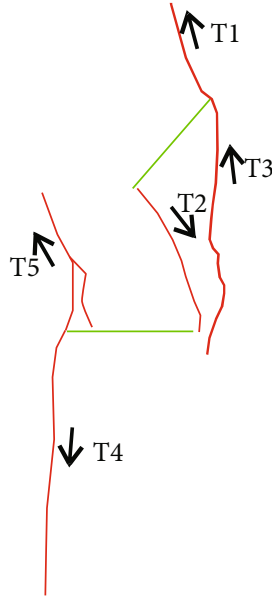

G50-50

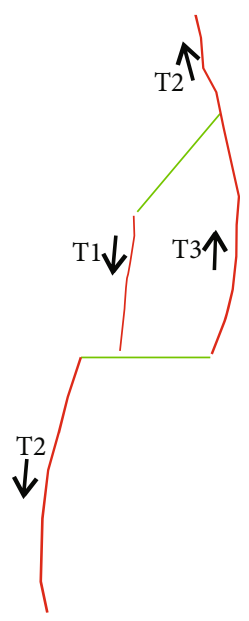

G100-50

(b)
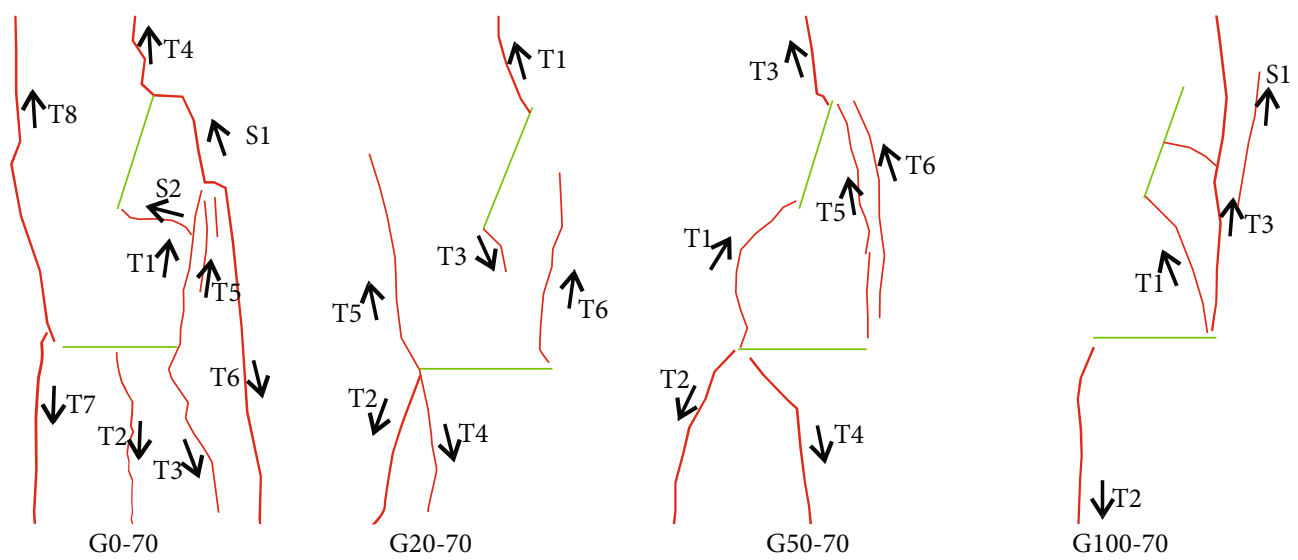

(c)

FIGURE 10: Sketch of the crack coalescence pattern observed around the rock bridge segment in the granite samples: (a) Samples have an inclined flaw of $20^{\circ}$ subjected to 0, 20,50, and 100 F-T cycles. (b) Samples have an inclined flaw of 50 subjected to 0, 20, 50, and 100 F-T cycles. (c) Samples have an inclined flaw of $70^{\circ}$ subjected to $0,20,50$, and $100 \mathrm{~F}$-T cycles. The thick green lines represent the flaws, and the thin red lines denote the cracks emanating from the flaws. The shear cracks and tensile cracks are marked with $\mathrm{S}$ and $\mathrm{T}$, respectively, with the following subscript number denoting the order of cracking.

between the left tip of the inclined flaw and the left tip of the horizontal flaw. For $N=20$ sample, tensile cracks were initiated from the right tip of the inclined flaw, one anti- crack propagation from the left of the horizontal crack, and two tensile cracks were initiated from the left tip of the horizontal flaw. For $N=50$ sample, tensile cracks were 

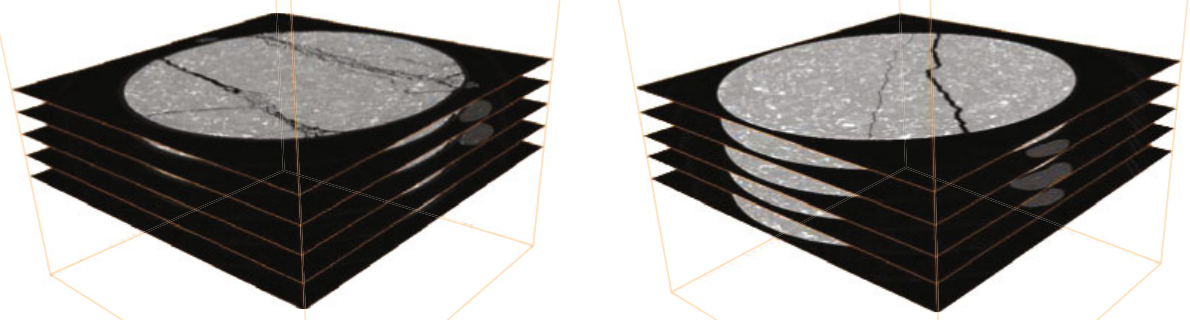

(a)

(b)

FIgURE 11: Scheme the positions of reconstructed CT slices to describe the brittle fracture of rock bridge, taking two samples for example (a) $\beta=20^{\circ}, \mathrm{F}-\mathrm{T}=0$ cycle; (b) $\beta=70^{\circ}, \mathrm{F}-\mathrm{T}=100$ cycle.
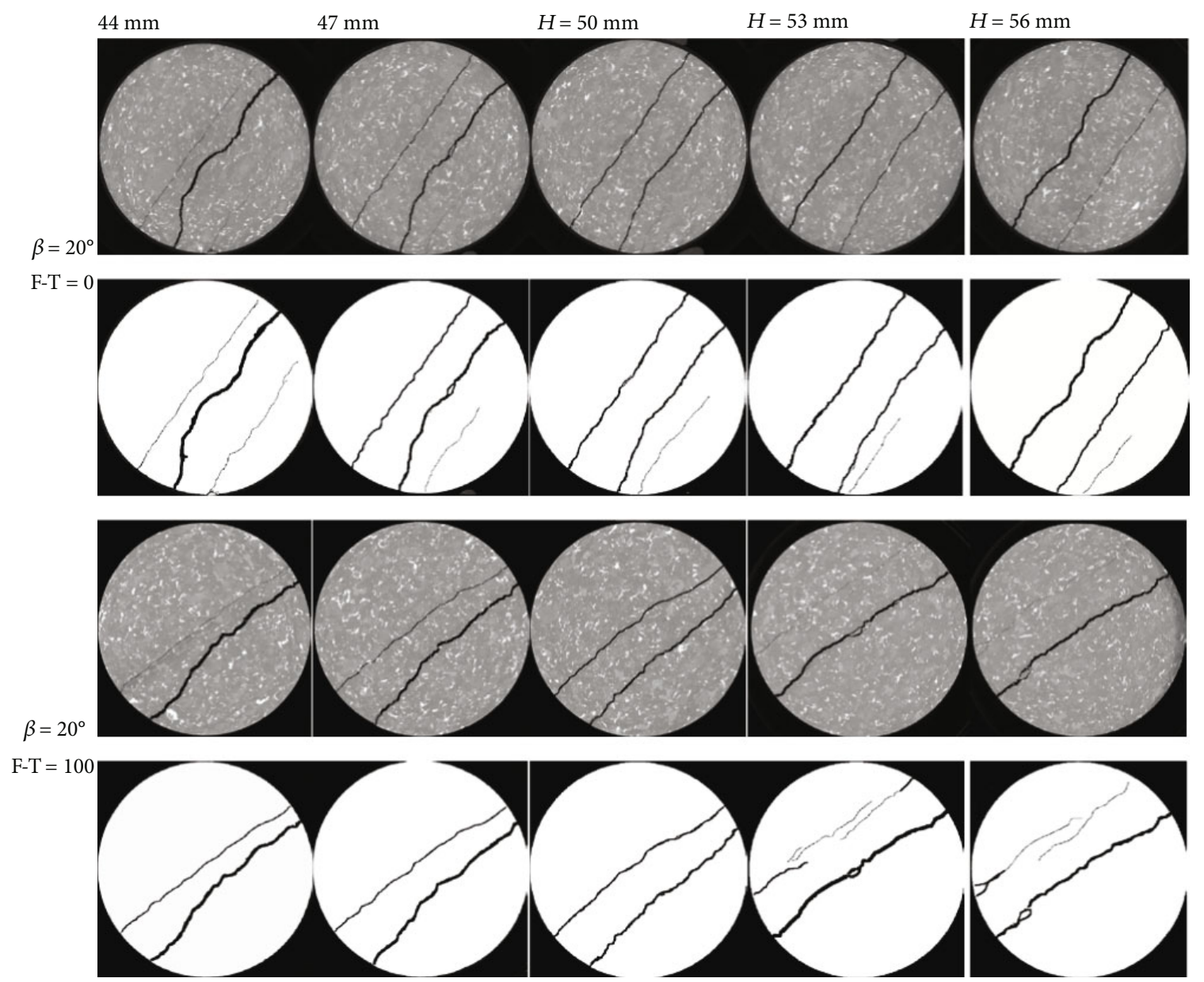

FIgURE 12: X-ray CT reconstruction images and crack pattern for the sample having an approach angle of $20^{\circ}$ subjected to 0 and 100 cycles.

initiated from the left tip of the inclined flaw and propagated to the left of the horizontal flaw, fracture surface forms to communicate the left tip of the inclined and horizontal flaw. The crack pattern is the simplest for $N=100$ sample, tensile cracks were imitated from the two tips of the horizontal flaw.

From the experimental results of crack coalescence behaviors for the granite sampling, it can be seen that the 

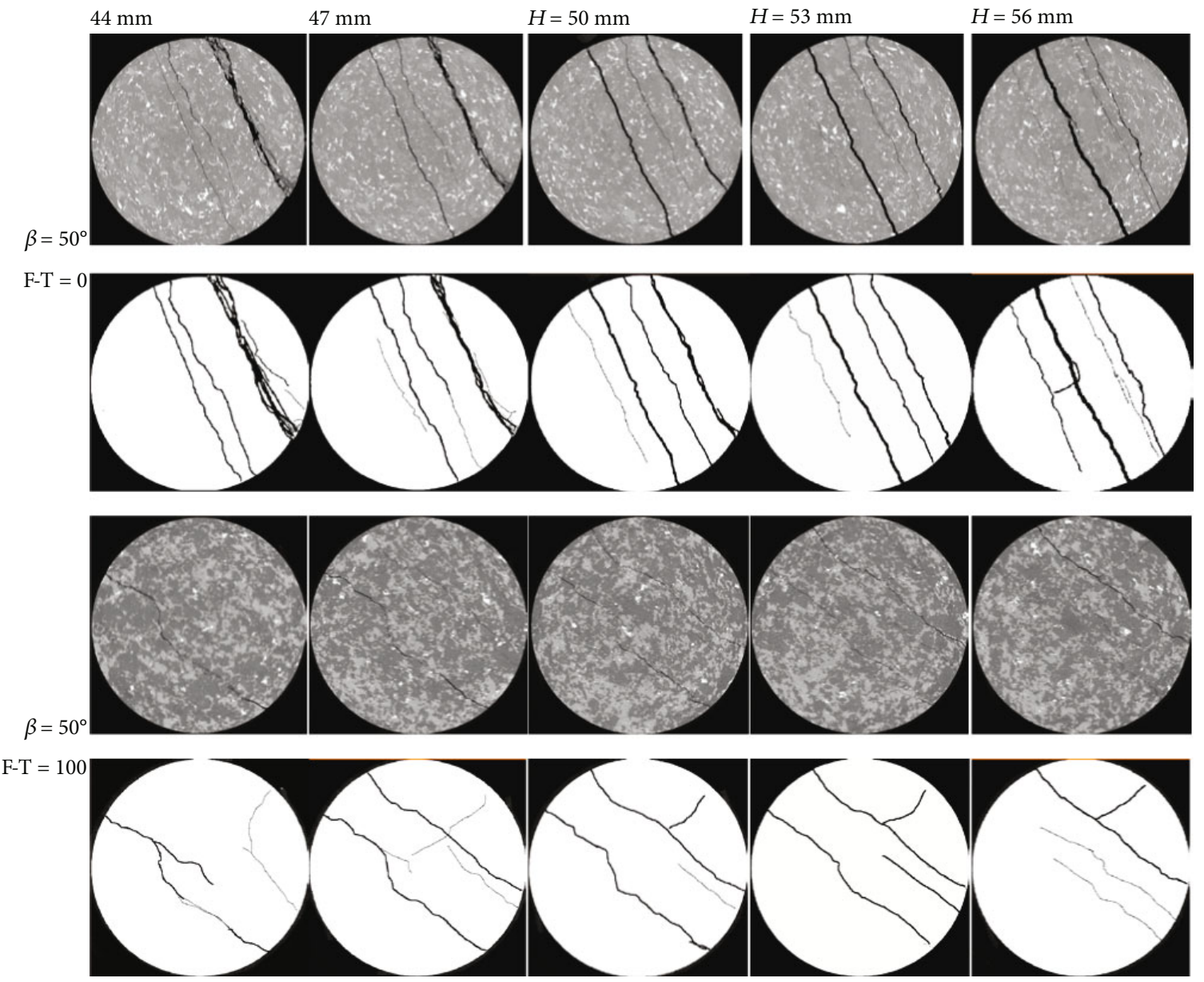

FIgURE 13: X-ray CT reconstruction images and crack pattern for the sample having approach an angle of $50^{\circ}$ subjected to 0 and 100 cycles.

crack initiation, propagation and coalescence behaviors are impacted by the approach angle of flaw and also the number of F-T cycles. Several studies have revealed the crack coalescence behaviors of rock or rock-like material under room temperature [18-20]; in this work, the crack propagation behaviors are almost the same with the previous studies. However, new insights have been found that the F-T fatigue damage also affects the coalescence behavior of the studied samples.

3.4. CT Visualization of Crack Pattern at Rock Bridge Area. Generally, the crack pattern of rock samples can only be observed from the sample surface with the naked eye. However, with the help of the high-resolution X-ray CT technique, the crack pattern inside the deformed sample can be detected [30]. In this work, posttest CT scanning was used for the granite samples containing two flaws subjected to F-T cycles and uniaxial compression. Because we are mainly focus on the crack morphology at the rock bridge area, the length of rock bridge is $20 \mathrm{~mm}$ before compression, and there, five CT slices were obtained for each sample, as shown in Figure 11. The scanning position is $44 \mathrm{~mm}$, $47 \mathrm{~mm}, 50 \mathrm{~mm}, 53 \mathrm{~mm}$, and $56 \mathrm{~mm}$ at the middle part of the rock sample.
The reconstructed CT images are shown in Figures 12-14. In these images, low-density regions can be observed in response to cracks. It can be seen that the distribution of the low-density regions is affected by the flaw approach and also the F-T cycles. Taking the sample without F-T treatment, for example, crack scale increases with the increasing approach angle, two crack bands can be observed for the sample with an inclined angle $70^{\circ}$. However, the crack pattern is relatively simple for the sample with an inclined angle of $20^{\circ}$. Basing on the original CT images, we further extract the crack pattern by using a series of digital imaging methods [30-32]. The crack pattern at the rock bridge area is also shown in Figures 12-14. It can be clearly seen that the morphology of the crack network becomes simple for the samples subjected to $100 \mathrm{~F}-\mathrm{T}$ cycles.

For the sample with an approach of $20^{\circ}$ (Figure 12), three sets of cracks exist for the sample without F-T treatment; however, two sets of cracks can be observed for the sample subjected to $100 \mathrm{~F}-\mathrm{T}$ cycles.

For the sample with an approach angle of $50^{\circ}$ (Figure 13), a crack zone can be observed at the right of the sample for the sample without F-T treatment. Four parallel cracks with larger aperture are distributed on the sample. However, the crack network is simple and the crack aperture is relatively small for the sample subjected to $100 \mathrm{~F}-\mathrm{T}$ cycles. 

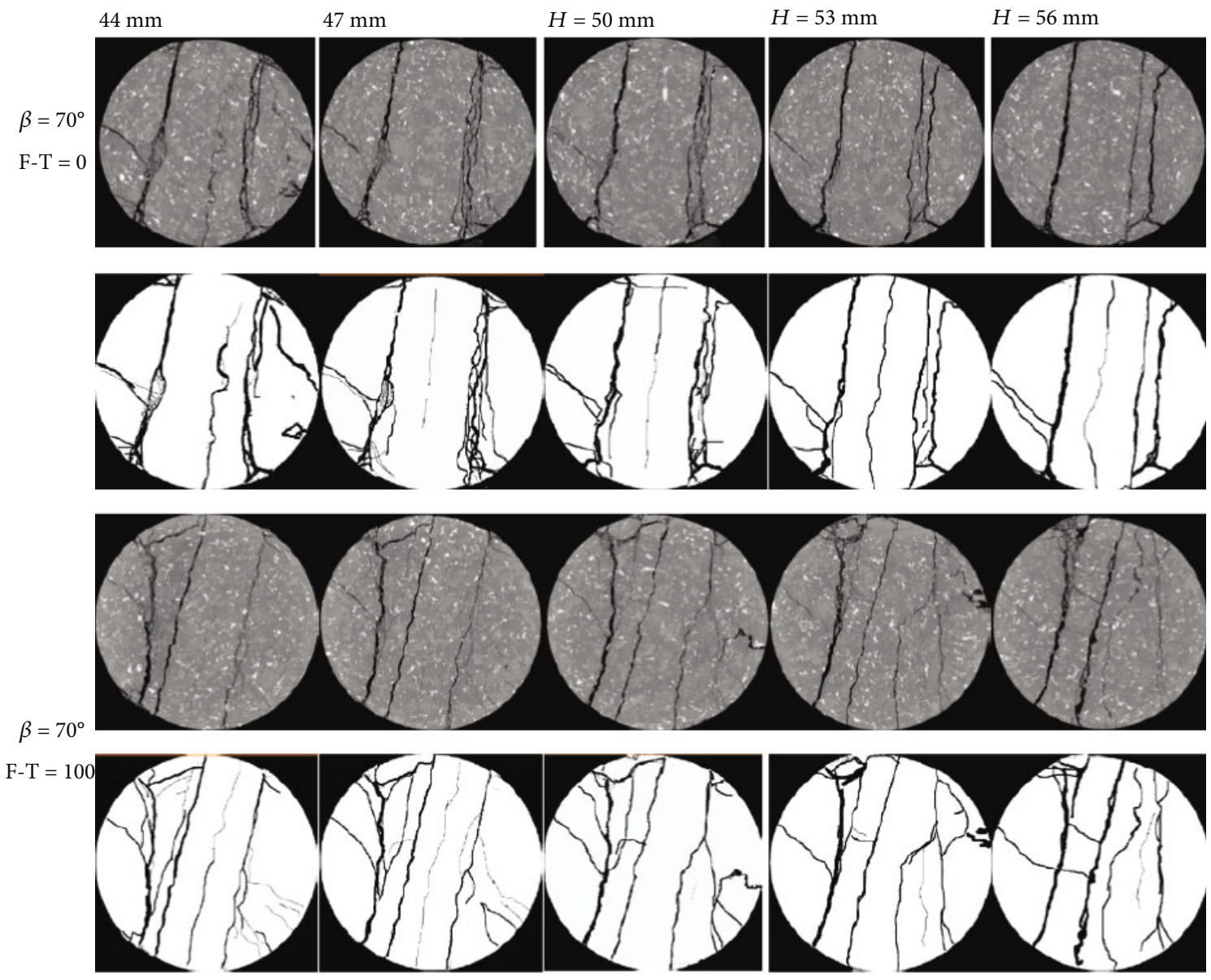

Figure 14: X-ray CT reconstruction images and crack pattern for the sample having an approach angle of $70^{\circ}$ subjected to 0 and 100 cycles.

For the sample with a high approach angle of $70^{\circ}$ and without F-T treatment (Figure 14), two crack zones can be observed at the left and right sides of the sample, many microcracks exist in the crack zone. This crack pattern indicates that fracture of the rock bridge is difficult, and much more energy is needed to communicate the preexisting upper inclined flaw and the horizontal flaw underneath. For the sample with $100 \mathrm{~F}-\mathrm{T}$ treatment, due to the high approach angle of the two flaws, the complex crack network is easily stimulated at the rock bridge area. However, no crack zone exists at the rock bridge and fracturing of the sample needs less energy than the sample without F-T treatment. The rock bridge is eerily to be fractured for the sample subjected to high F-T cycles. To roughly reveal the impact of the F-T cycle on the fracturing of the rock bridge area, an index of fracture degree is defined as the ratio of the total crack area to the total section area of the CT images. In this work, because only five CT slices were obtained for each tested sample, the calculated index cannot reflect the fracture degree accurately; however, the change trend can be reflected using this method. Table 5 lists the fracture degree for the tested samples with approach angles of $20^{\circ}, 50^{\circ}$, and $70^{\circ}$, respectively. It can be seen that the fracture degree is smaller for samples subjected to $100 \mathrm{~F}-\mathrm{T}$ cycles.
TABLE 5: Fracture degree of the rock bridge area for samples with different approach angles.

\begin{tabular}{llll}
\hline F-T cycle & $\beta=20^{\circ}$ & $\beta=50^{\circ}$ & $\beta=70^{\circ}$ \\
\hline $\mathrm{F}-\mathrm{T}=0$ & 0.02577 & 0.04955 & 0.10706 \\
$\mathrm{~F}-\mathrm{T}=100$ & 0.01855 & 0.02703 & 0.08506 \\
\hline
\end{tabular}

\section{Conclusions}

In this study, the mechanical properties and crack coalescence pattern of granite containing two flaws subjected to artificial, repeated freeze-thaw cycles have been studied. In particular, the crack pattern at the rock bridge area was investigated using both the macroscopic crack descriptions and the posttest CT scanning technique. The effects of F-T cycles on the crack network morphology at the rock bridge area are quantitatively studied by defining an index basing on the CT images. The main conclusions drawn from this study are as follows:

(1) Mechanical properties of rock are deteriorated after repeated F-T fatigue damage, the peak stress decreases with increasing F-T cycles. Stress drop phenomenon is observed due to the existence of the 
preexisting two flaws, the locking structure at the rock bridge area is contributed to improve the overall integrity of rock. The number of stress drop points decreases with increasing F-T cycle, this reflects the increasing damage resulting from the frost heaving pressure on the flaws

(2) Crack pattern description reveals the failure mechanism of the rock, three kinds of cracks were observed, tensile cracks were firstly initiated from the flaw tip for all the samples, and shear cracks were prone to form for the sample subjected to low F-T cycles. The failure mode for rock experiencing a low F-T cycle is a combination of tensile and shears cracking. However, it is primary for the sample subjected to high F-T treatment to have tensile cracking. Macroscopic pattern description finds that a crack pattern is simple for the sample subjected to high F-T treatment

(3) Posttest CT scanning offers a unique insight into the internal crack pattern for the rock without and with F-T treatment. The CT images reveal the differential crack network morphology, and the crack pattern is influenced by the F-T effects and the flaw approach angle. It is found that the fracture degree deceases with increasing F-T cycles and increases with increasing approach angle. It is suggested that the F-T treatment has influences on fatigue damage and the associated macroscopic fracture morphology

(4) From the macroscopic crack pattern description and CT imaging analysis, crack initiation and propagation are impacted by the F-T treatment and flaw approach angle. This finding suggests that the rock bridge is easily fractured with high F-T treatment. Thus, the investigation of F-T damage and the associated facture behaviors of flawed rock are of key interest in predicting the stability of rock mass and rock structure in cold regions

\section{Data Availability}

The experimental data used to support the findings of this study are included within the article.

\section{Conflicts of Interest}

The authors declare no conflict of interest.

\section{Acknowledgments}

This study was supported by the National Key Technologies Research \& Development program (2018YFC0808402), the Fundamental Research Funds for the Central Universities (FRF-TP-19-004B1), the State Key Laboratory of Geohazard Prevention and Geoenvironment Protection (Chengdu University of Technology) (SKLGP2019K017), and the Beijing Natural Science Foundation (82020033).

\section{References}

[1] R. Li, H. Bing, Y. Wu, J. Zhou, and Z. Xiang, "Altitudinal patterns and controls of trace metal distribution in soils of a remote high mountain, Southwest China," Environmental Geochemistry and Health, vol. 40, no. 1, pp. 505-519, 2018.

[2] A. J. Wang, "Global resource structure and its perspective," Diqiu Xuebao (Acta Geoscientica Sinica), vol. 31, no. 5, pp. 621-627, 2010.

[3] M. Hori and H. Morihiro, "Micromechanical analysis on deterioration due to freezing and thawing in porous brittle materials," International Journal of Engineering Science, vol. 36, no. 4, pp. 511-522, 1998.

[4] W. Fang, N. Jiang, and X. Luo, "Establishment of damage statistical constitutive model of loaded rock and method for determining its parameters under freeze-thaw condition," Cold Regions Science and Technology, vol. 160, pp. 31-38, 2019.

[5] J. Park, C. U. Hyun, and H. D. Park, "Changes in microstructure and physical properties of rocks caused by artificial freeze-thaw action," Bulletin of Engineering Geology and the Environment, vol. 74, no. 2, pp. 555-565, 2015.

[6] T. Yamabe and K. M. Neaupane, "Determination of some thermo-mechanical properties of Sirahama sandstone under subzero temperature condition," International Journal of Rock Mechanics and Mining Sciences, vol. 38, no. 7, pp. 1029-1034, 2001.

[7] M. Takarli, W. Prince, and R. Siddique, "Damage in granite under heating/cooling cycles and water freeze-thaw condition," International Journal of Rock Mechanics and Mining Sciences, vol. 45, no. 7, pp. 1164-1175, 2008.

[8] X. J. Tan, W. Z. Chen, J. P. Yang, and J. J. Cao, "Laboratory investigations on the mechanical properties degradation of granite under freeze-thaw cycles," Cold Regions Science and Technology, vol. 68, no. 3, pp. 130-138, 2011.

[9] M. H. Ghobadi and R. Babazadeh, "An investigation on the effect of accelerated weathering on strength and durability of tertiary sandstones (Qazvin province, Iran)," Environment and Earth Science, vol. 73, no. 8, pp. 4237-4250, 2015.

[10] A. Al-Omari, K. Beck, X. Brunetaud, Á. Török, and M. Al-Mukhtar, "Critical degree of saturation: A control factor of freeze-thaw damage of porous limestones at Castle of Chambord, France," Engineering Geology, vol. 185, pp. 71-80, 2015.

[11] D. T. Nicholson and F. H. Nicholson, "Physical deterioration of sedimentary rocks subjected to experimental freeze-thaw weathering," Earth Surface Processes and Landforms, vol. 25, no. 12, pp. 1295-1307, 2015.

[12] F. Bayram, "Predicting mechanical strength loss of natural stones after freeze-thaw in cold regions," Cold Regions Science and Technology, vol. 83-84, pp. 98-102, 2012.

[13] S. B. Huang, Q. S. Liu, Y. Z. Liu, Y. S. Kang, A. P. Cheng, and Z. Y. Ye, "Frost heaving and frost cracking of elliptical cavities (fractures) in low- permeability rock," Engineering Geology, vol. 234, pp. 1-10, 2018.

[14] P. Wang, J. Y. Xu, S. Liu, H. Y. Wang, and S. H. Liu, "Static and dynamic mechanical properties of sedimentary rock after freeze-thaw or thermal shock weathering," Engineering Geology, vol. 210, pp. 148-157, 2016.

[15] Z. T. Bieniawski, "Mechanism of brittle fracture of rock: part II-experimental studies," International Journal of Rock 
Mechanics and Mining Sciences \& Geomechanics Abstracts, vol. 4, no. 4, pp. 407-423, 1967.

[16] A. Bobet and H. H. Einstein, "Fracture coalescence in rocktype materials under uniaxial and biaxial compression," International Journal of Rock Mechanics and Mining Sciences, vol. 35, no. 7, pp. 863-888, 1998.

[17] L. N. Y. Wong and H. H. Einstein, "Crack coalescence in molded gypsum and Carrara marble: part 1. Macroscopic observations and interpretation," Rock Mechanics and Rock Engineering, vol. 42, no. 3, pp. 475-511, 2009.

[18] Y. H. Huang, S. Q. Yang, W. L. Tian, W. Zeng, and L. Y. Yu, "An experimental study on fracture mechanical behavior of rock-like materials containing two unparallel fissures under uniaxial compression," Acta Mechanica Sinica, vol. 32, no. 3, pp. 442-455, 2016.

[19] Y. H. Huang, S. Q. Yang, and J. Zhao, “Three-dimensional numerical simulation on triaxial failure mechanical behavior of rock-like specimen containing two unparallel fissures," Rock Mechanics and Rock Engineering, vol. 49, no. 12, pp. 47114729, 2016.

[20] Y. P. Li, L. Z. Chen, and Y. H. Wang, "Experimental research on pre-cracked marble under compression," International Journal of Solids and Structures, vol. 42, no. 9-10, pp. 25052516, 2005.

[21] Y. Zhao, L. Zhang, W. Wang, C. Pu, W. Wan, and J. Tang, "Cracking and stress-strain behavior of rock-like material containing two flaws under uniaxial compression," Rock Mechanics and Rock Engineering, vol. 49, no. 7, pp. 26652687, 2016.

[22] S. Q. Yang, X. R. Liu, and H. W. Jing, "Experimental investigation on fracture coalescence behavior of red sandstone containing two unparallel fissures under uniaxial compression," International Journal of Rock Mechanics and Mining Sciences, vol. 63, pp. 82-92, 2013.

[23] J. P. Petit and M. Barquins, "Can natural faults propagate under mode II conditions?," Tectonics, vol. 7, no. 6, pp. 1243-1256, 1988.

[24] J. Q. Mu, X. J. Pei, R. Q. Huang, N. Rengers, and X. Q. Zou, "Degradation characteristics of shear strength of joints in three rock types due to cyclic freezing and thawing," Cold Regions Science and Technology, vol. 138, pp. 91-97, 2017.

[25] S. B. Huang, Q. S. Liu, Y. Z. Liu, Z. Y. Ye, and A. P. Cheng, "A fully coupled thermo-hydro-mechanical model including the determination of coupling parameters for freezing rock," International Journal of Rock Mechanics and Mining Sciences, vol. 103, pp. 205-214, 2018.

[26] S. Huang, Y. Liu, Y. Guo, Z. Zhang, and Y. Cai, "Strength and failure characteristics of rock-like material containing single crack under freeze-thaw and uniaxial compression," Cold Regions Science and Technology, vol. 162, pp. 1-10, 2019.

[27] Y. Lu, X. Li, and A. Chan, "Damage constitutive model of single flaw sandstone under freeze-thaw and load," Cold Regions Science and Technology, vol. 159, pp. 20-28, 2019.

[28] X. P. Zhou, Y. Niu, J. Z. Zhang, X. C. Shen, Y. Zheng, and F. Berto, "Experimental study on effects of freeze-thaw fatigue damage on the cracking behaviors of sandstone containing two unparallel fissures," Fatigue \& Fracture of Engineering Materials \& Structures, vol. 42, no. 6, pp. 1322-1340, 2019.

[29] Y. Wang, C. H. Li, and Y. Z. Hu, "Experimental investigation on the fracture behaviour of black shale by acoustic emission monitoring and CT image analysis during uniaxial compres- sion," Geophysical Journal International, vol. 213, no. 1, pp. 660-675, 2018.

[30] Y. Wang, C. H. Li, and Y. Z. Hu, "Use of X-ray computed tomography to investigate the effect of rock blocks on meso-structural changes in soil-rock mixture under triaxial deformation," Construction and Building Materials, vol. 164, pp. 386-399, 2018.

[31] J. Otani and Y. Obara, X-ray CT for Geomaterials, Balkema, Lisse, 2004.

[32] G. Viggiani, N. Lenoir, P. Be'suelle, M. Di Michiel, J. Desrues, and M. Kretzschmer, "X-ray microtomography for studying localized deformation in fine-grained geomaterials under triaxial compression," Comptes Rendus Mécanique, vol. 332, no. 10, pp. 819-826, 2004. 